\title{
Effect of weld angle on the creep rupture life of ferritic/austenitic dissimilar weld interfaces under remote mode I fracture
}

\author{
Jianan $\mathrm{Hu}^{\mathrm{a}, \mathrm{b}, 1}$, Elsiddig Elmukashfi ${ }^{\mathrm{a}}$, Takuya Fukahoric ${ }^{\mathrm{c}}$, Toshihide Igaric ${ }^{\mathrm{c}}$, \\ Yasuharu Chuman ${ }^{\mathrm{c}}$, Alan C.F. Cocks ${ }^{\mathrm{a}}$ \\ ${ }^{a}$ Department of Engineering Science, University of Oxford, Parks Road, OX1 3PJ, UK \\ ${ }^{b}$ Sente Software Ltd, Surrey Technology Centre, Guildford, GU2 7YG, UK \\ ${ }^{c}$ Research \& Innovation Centre, Mitsubishi Heavy Industry. Ltd, 717-1, Fukahori-machi, 5-chome, Nagasaki, 851-0392, Japan
}

\begin{abstract}
Dissimilar metal welded structures (DMWs) used extensively in conventional and nuclear power plants can suffer from in-service failures at the dissimilar interface with a much reduced life compared to similar metal weld counterparts at the same operating stress and temperature. This paper evaluates the effect of weld angle on the interface creep failure mode of two-dimensional DMW plates consisting of a ferritic steel P91 and an Inconel 82 filler metal within a finite element (FE) framework. A physical cavity growth damage zone model is developed to describe the damage accumulation at the interface, which naturally takes into account the local mode mixity. The material parameters are calibrated against standard $90^{\circ}$ weld creep rupture data and used to predict the rupture life of DMWs with a range of axial loads and reduced weld angles $\left(75^{\circ}, 60^{\circ}, 45^{\circ}\right.$ and $\left.30^{\circ}\right)$. The predicted results match reasonably well with the limited interface failure data for a $45^{\circ}$ weld angle. This work also provides additional evidence and insights regarding the improvement of interface creep rupture life of DMWs in power plant pipelines, in particular: (1) Compared with a $45^{\circ}$ weld angle, a $60^{\circ}$ weld angle is more detrimental to the creep life and should be avoided in actual components - on the contrary, damage tolerance can be promoted by designing and adopting weld angles smaller than $45^{\circ}$, which can have lives exceeding that of standard $90^{\circ}$ welded components; (2) A weld interface with alternating weld angles/paths is expected to enable a greater fraction of the creep rupture life to be taken up with crack propagation compared with a flat weld interface, which also increases the probability of damage detection; (3) A fully constrained boundary condition is beneficial to the creep rupture life compared with a free boundary condition; (4) For weld angles less than $90^{\circ}$, the diversion of the crack into the HAZ is less likely compared with a $90^{\circ}$ weld angle.
\end{abstract} Type IV failure mode through the FGHAZ is also less likely to occur.

Keywords: P91/Inco82 dissimilar metal weld; Mix-mode interface creep rupture; Weld angle; Damage zone model.

${ }^{1}$ Corresponding author: Tel.: +44(0)1483685478. E-mail address: jianan.hu@ sentesoftware.co.uk 


\section{Nomenclature}

\begin{tabular}{|c|c|}
\hline$\alpha$ & Coefficient of thermal expansion (CTE) \\
\hline$\dot{\varepsilon}_{0}\left(\dot{\varepsilon}_{0 H}\right)$ & Strain rate in the base metal (heat affected zone, HAZ) at a reference stress $\sigma_{0}$ \\
\hline$n$ & Power-law creep stress exponent of continuum material \\
\hline$m$ & Power-law creep constant of interface zone \\
\hline$k$ & Softening constant for heat affected zone (HAZ) \\
\hline$b$ & Nucleation constant for heat affected zone (HAZ) \\
\hline$N$ & Number of nucleated cavities in heat affected zone (HAZ) \\
\hline$N_{c}$ & Critical number of nucleated cavities in heat affected zone (HAZ) for Type IV failure \\
\hline$\delta_{n}\left(\delta_{t}\right)$ & Normal (tangential) separation of interface zone \\
\hline$T_{n}\left(T_{t}\right)$ & Normal (tangential) traction of interface zone \\
\hline$\delta_{n}^{c r}\left(\delta_{t}^{c r}\right)$ & Normal (tangential) separation of interface zone resulted from creep \\
\hline$f$ & Area fraction of cavities at each interface zone element \\
\hline$h$ & Height of a unit cylinder-shape cell with a pore at the interface \\
\hline$l$ & Half of the length of a unit cylinder-shape cell with a pore at the interface \\
\hline$\dot{\delta}_{0}$ & Creep separation rate of interface zone at a reference traction $T_{0}$ \\
\hline$f_{c}$ & Critical area fraction of cavities for interface zone element failure \\
\hline
\end{tabular}




\section{Introduction}

Dissimilar-metal welding refers to the joining of two different alloy systems. The use of dissimilar metal welds (DMWs) provides a cost-effective manufacturing solution to nuclear and thermal power plant operators with the advantage of optimizing the merits of different materials in a single application [1], particularly in situations where there is a temperature gradient along the component. However, this can give rise to a trade-off between performance and affordability, which is influenced by the complexities of the creep behavior of the DMW components at elevated temperatures due to the material mismatch, use of different filler metals, and variable dimensions and shapes of welds $[2,3]$. The structural integrity assessment of DMW components requires a comprehensive understanding and evaluation of the creep rupture properties [4-6].

Premature failure of welds between two dissimilar materials have been a common occurrence in power generating plant [4, 5, 7]. The structural complexities have given rise to enriched in-service creep failure modes in DMW components compared with similarmetal welded components. A schematic showing the different possible failure modes is presented in Fig. 1. In a simple uniaxial creep rupture test on a cross-weld component, failure can occur in the weld metal (Type I), originate in the weld metal but propagate through the coarse-grain heat affected zone (CGHAZ, Type II), occur entirely within the coarse-grain heat affected zone (CGHAZ) (Type III), in the fine-grain heat affected zone (FGHAZ) (Type IV), in the base (parent) metal (Type V), or at the dissimilar weld interface (Type VI or VII, e.g. between HAZ and the filler metal), with the last of these representing a unique failure mode for DMWs $[4,5,8]$. For the interface failure mode, a crack initiates from a feature that gives rise to a local stress concentration, usually where the interface meets the free surface, and Type VII refers to the subsequent propagation of the crack strictly along the interface, while Type VI refers to an eventual diversion into the HAZ, which can be regarded as a combination of Type VII and Type III-IV [8]. Factors that determine the dominant failure mode include externally applied load, operating temperature, weld geometry, and environmental conditions [3-5, 9].

Type III Type II Type I
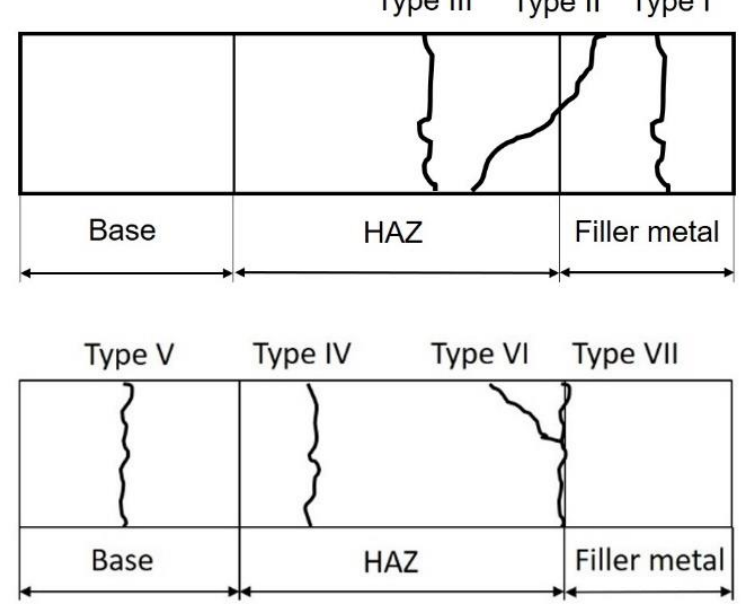

Fig. 1. A schematic showing all possible failure modes of a dissimilar metal welded (DMW) joints.

In this work, we focus on the interface failure mode, Type VI or VII, in a DMW consisting of a ferritic steel P91 and an Inconel 82 filler metal, which has been shown to dominate at relatively low stresses and long times to failure and exhibits a different dependency on load compared with the other failure modes described above [4, 5]. Two major factors have been determined to promote interface failure: (1) discontinuous mechanical properties across the dissimilar interface, such as hardness, thermal expansion coefficient and creep rate [4]; (2) carbon migration from the low alloy side to high alloy side at the interface, causing the formation of a short range carbon depleted zone (CDZ), a carbon enriched zone (CEZ) [9-13], and elongated carbide precipitates along the interface, which do not dissolve at the typical operation temperatures of the DMW component and provide ideal sites for 
the nucleation of cavities $[4,14]$. The mechanical interaction between these different regions can generate localized stress triaxiality detrimental to the creep life. However, despite the metallurgical findings, most of the theoretical and numerical simulation studies have concentrated on the mechanical property mismatch between the two materials either side of the dissimilar interface [14-19] but not the detailed microstructure evolution, in particular the creep cavity growth, along the interface. Due to the shortage of quantitative microstructural data available to critically assess the applicability, robustness and validity of different models, an in-depth understanding of the failure mechanisms associated with the local microstructure is not yet available. In addition, very little research has been directed to optimization of the weld angle with respect to the principal loading direction, which is another life critical issue.

In this study, we evaluate the effect of weld angle on the creep rupture at a dissimilar welded interface between a ferritic 9Cr$1 \mathrm{MoVNb}$ (designated P91) steel and austenitic Inconel 82 filler metal (designated Inco82) at 550 ${ }^{\circ} \mathrm{C}$. We consider the situation where the load is applied perpendicular to the $90^{\circ}$ weld interface. As the weld angle changes, mix-mode conditions become more and more pronounced at the interface. Monotonic uniaxial creep rupture data on a DMW pipe is available for weld angles of $90^{\circ}$ and $45^{\circ}[20]$, which shows a much reduced creep rupture life at the ferritic/austenitic dissimilar interface for the $45^{\circ}$ weld compared with when the weld angle is $90^{\circ}$ (Fig. 2). In our previous work [8, 21], we have developed an analytical and computational Kachanov-type interface damage zone approach in which the damage growth along the dissimilar interface is a function of only the normal traction and separation perpendicular to the interface. Here we extend our work by developing a physical creep cavity growth interface zone model based on the work conducted in [22] to take into account the influence of the component of the traction tangential to the interface on the development of damage. This is then implemented in the commercial finite element code ABAQUS to capture the localized mix-mode condition at the interface, the normal-tangential traction-separation interaction and the development of damage and subsequent growth of an interfacial crack. For simplicity, only a two-dimensional plate geometry is considered here. Extension of this work to consider the full 3D geometry is presented elsewhere [23]. We first take the system with a $90^{\circ}$ weld interface to calibrate the parameters against the available failure data shown in Fig. 2. These parameters are subsequently used to evaluate several other weld angles $\left(75^{\circ}, 60^{\circ}, 45^{\circ}\right.$ and $\left.30^{\circ}\right)$. Results are compared in terms of the variation in normal-tangential traction and the relative timescales for crack initiation and propagation. The effect of different boundary conditions and a pre-existing crack is also explored, taking the DMW system with a $45^{\circ}$ weld angle as an example. The aim is to probe the sensitivity of creep rupture life to the weld angle and boundary conditions in order to provide guidelines for improving design and welding procedures for increasing reliability and longevity of DMWs.

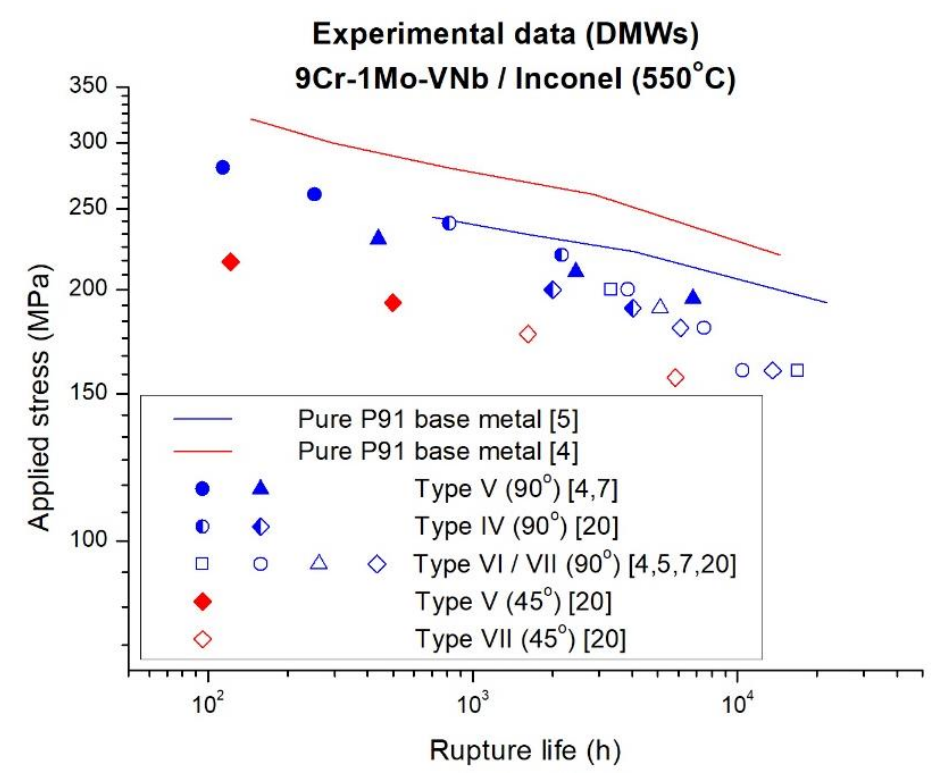

Fig. 2. Comparison of experimental creep rupture lives data of P91/Inco82 dissimilar metal welded (DMW) joints at $550^{\circ} \mathrm{C}$ with two different weld angles $\left(90^{\circ}\right.$ and $\left.45^{\circ}\right)$. Reference for the data can be found in $[4,5,7,20]$. 


\section{Creep modelling of DMW systems}

The creep properties have been shown to vary in different regions of a typical DMW system, i.e. base (parent) metal(s), heataffected zone (HAZ), filler metal, and the interface between the two dissimilar materials (i.e. the ferritic steel and INCONEL) [4, 8, 24]. As our main focus is on creep cavity growth at the interface zone, deformation models for other regions have been simplified and are briefly introduced here. One can refer to [8] for a more detailed description.

\subsection{Base metal and filler metal(power-law)}

At elevated temperatures, deformation in the base (ferritic steel) and filler (INCONEL) metals is described by Eq. (1) below, with the creep behaviour modelled by a simple power-law relationship. Damage and softening in these parts are ignored due to the negligible effect compared with that in the HAZ and interface over the range of stress of interest in this report, for which interface failure dominates [8]. For these regions:

$$
\dot{\varepsilon}_{i j}=\dot{\varepsilon}_{i j}^{e}+\dot{\varepsilon}_{i j}^{c r}+\dot{\varepsilon}_{i j}^{t h}=\frac{1+v}{E}\left(\dot{\sigma}_{i j}-\frac{v}{1+v} \dot{\sigma}_{k k} \delta_{i j}\right)+\frac{3}{2} \dot{\varepsilon}_{0}\left(\frac{\sigma_{e}}{\sigma_{0}}\right)^{n-1} \frac{s_{i j}}{\sigma_{0}}+\alpha \dot{T}_{t e m p}
$$

where the superscripts " $e, c r, t h$ " refer to elasticity, creep and thermal expansion. Material-specific properties include Young's modulus $E$, Poisson's ratio $v$, reference creep rate $\dot{\varepsilon}_{0}$ and stress $\sigma_{0}$, linear coefficient of thermal expansion $\alpha(\mathrm{CTE})$ and the steady state creep exponent $n$.

\subsection{Heat-affected zone (HAZ) (power-law + softening)}

At elevated temperatures, deformation in the HAZ is described by Eq. (1) but with the creep model modified to incorporate the effect of strain softening, such that $[25,26]$ :

$$
\dot{\varepsilon}_{i j}^{c r}=\frac{3}{2} \dot{\varepsilon}_{0 H}\left(\frac{\sigma_{e}}{\sigma_{0}}\right)^{n-1} \frac{s_{i j}}{\sigma_{0}} \exp k \bar{\varepsilon}^{c r}
$$

where $\bar{\varepsilon}^{c r}$ is the total effective accumulated creep strain. This is underpinned by two aspects. Firstly, the Type IV failure mode that occurs in the HAZ (predominantly in the fine-grained heat affected zone, FGHAZ [27]) and results from cavity nucleation and growth, shares a similar applied stress range with the interface failure mode $[4,5]$. Secondly, the Type VI interface failure mode can divert from propagating along the interface, to penetrating into the HAZ towards the end of life. As a consequence, the effect of softening on the deformation behavior of the HAZ must be incorporated. Cavitation in the HAZ has also been taken into account by a simple Type IV damage accumulation model developed by Gonzales et al [28], assuming the Type IV failure is controlled by the nucleation/formation (number density $N$ ) of grain-sized pores. They propose that the rate of increase of the number density of large pores is given by

$$
\dot{N}=b \dot{\varepsilon}_{e}^{c r}\left(\frac{4}{9}+\frac{20}{9} X^{2}\right): \quad X=\frac{3 \sigma_{m}}{2 \sigma_{e}}
$$

where $\dot{N}$ is nucleation rate, $\dot{\varepsilon}_{e}^{c r}$ is the effective creep rate, $\sigma_{m}$ is the hydrostatic component of stress, and $X$ is the triaxiality factor. The critical number density $\left(N_{c}\right)$ of the grain-sized cavities for Type IV failure in P91 ferritic steel has been identified by Igari et al [29] and Fukahori et al [30] to be $N_{c}=40,000 / \mathrm{mm}^{2}$ based on the measurement of the average grain size in P91 FGHAZ. Following our previous work [8], we do not further consider the complexity of the effect of cavitation on the creep behavior of HAZ but track and store the ratio $N / N_{c}$ as a state variable to provide an indication of damage evolution in the HAZ, while a different form of damage 
accumulates at the interface (considered in the next sub-section) which leads to crack initiation and propagation along the interface. Additional material parameters in Eqs. (2) and (3) include the softening constant $k$, reference creep rate for HAZ $\dot{\varepsilon}_{0 H}$, and a damage constant $b$. Note that the HAZ can be sub-divided into a thin coarse-grained heat affected zone (CGHAZ) adjacent to the interface, an intercritical heat affected zone (ICHAZ) adjacent to the base metal, and a thick fine-grained heat affected zone (FGHAZ) between the CGHAZ and ICHAZ [4, 14]. Parameters may vary across these three layers. In practice, we only consider the CGHAZ and FGHAZ and ignore the ICHAZ in this study. We further assume that the CGHAZ has the same creep properties as the base metal $\left(\dot{\varepsilon}_{0 H_{-} C G H A Z}=\dot{\varepsilon}_{0 \_ \text {base }}, \sigma_{0 \_ \text {CGHAZ }}=\sigma_{0 \_ \text {base }}\right)[8,30,31]$.

\subsection{Interface region (creep cavity growth)}

Here we focus on a physical cavity growth traction-separation rate relationship for the interface zone, which is developed from a previous model proposed by Yalcinkaya and Cocks [22]. This model adopts a similar idealisation to the extensively used models of McClintock [32] and Cocks and Ashby [33]. It captures the interaction between normal and tangential tractions and separations, and thus is able to simulate mix-mode fracture problems. The model assumes the pores are nucleated early in life and considers the process of cavity growth in a constrained layer at an interface, either a grain boundary or an interface between two dissimilar materials. It can be further combined with models for the nucleation of cavities, but in the absence of suitable data for the nucleation process and to limit the number of parameters that need to be determined, we assume that the development of damage at the interface is dominated by the growth of the cavities.

We assume the interface plane is composed of multiple identical cylindrical cells with a height $\boldsymbol{h}$ and diameter $\mathbf{2 l}$, subject to normal and tangential tractions $T_{n}, T_{t}$, giving rise to normal and tangential separations $\delta_{n}, \delta_{t}$ (Fig. 3). An array of pores exists within the plane with each representative cell containing an idealized cylindrical pore with radius $\boldsymbol{a}$ at a given instant, thus the initial volume of a pore can be expressed as $\boldsymbol{\pi} \boldsymbol{a} \boldsymbol{0}^{2} \boldsymbol{h} \boldsymbol{h}$. Assume a boundary condition that each cell is constrained such that deformation is concentrated in the cavitated zone, thus $l$ remains constant and the in-plane radial displacement and rate $u=0, \dot{u}=0$ at $r=l$. Using a polar coordinate system, combining the boundary conditions, the plastic incompressibility condition $\left(\dot{\varepsilon}_{r}+\dot{\varepsilon}_{\theta}+\dot{\varepsilon}_{z}=0\right.$ ), and small strain relation $\dot{\varepsilon}_{z}=\dot{h} / h, \dot{\varepsilon}_{\theta}=\dot{u} / r, \dot{\varepsilon}_{r}=d \dot{u} / d r$, the radial and circumferential strain rates can be obtained

$$
\begin{gathered}
\dot{u}=\frac{\dot{\varepsilon}_{z} r}{2}\left(\frac{l^{2}}{r^{2}}-1\right) \text { and } \dot{\varepsilon}_{r}=-\left(\dot{\varepsilon}_{\theta}+\dot{\varepsilon}_{z}\right)=-\frac{\dot{\varepsilon}_{z}}{2}\left(\frac{l^{2}}{r^{2}}+1\right) \\
\left.\dot{\varepsilon}_{\theta}=\frac{l^{2}}{r^{2}}-1\right)
\end{gathered}
$$
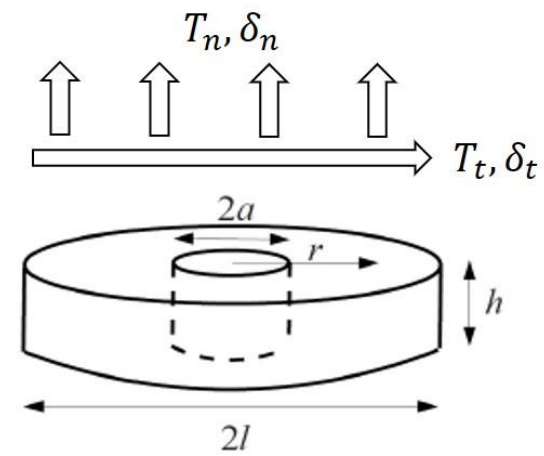

Fig. 3 Idealization of pores within a plane as cylinders

Next we consider the situation where the interface material consists of a power law creeping material. It proves convenient to express 
the response in terms of a convex stress potential $\psi$

$$
\psi=\frac{1}{m+1} \dot{\varepsilon}_{0} \sigma_{0}\left(\frac{\sigma_{e}}{\sigma_{0}}\right)^{m+1}
$$

The inelastic strain-rate is then given by (equivalent to the power-law in Eq. 1)

$$
\dot{\varepsilon}_{i j}=\frac{\partial \psi}{\partial \sigma_{i j}}=\frac{3}{2} \dot{\varepsilon}_{0}\left(\frac{\sigma_{e}}{\sigma_{0}}\right)^{m-1} \frac{s_{i j}}{\sigma_{0}}
$$

As demonstrated by Cocks [34], the constitutive response for the interface zone can be written in an equivalent form, i.e. we can define a macroscopic potential

$$
\psi=\frac{1}{m+1} \dot{\delta}_{0} \sigma_{0}\left(\frac{T_{e}}{\sigma_{0}}\right)^{m+1}
$$

such that

$$
\dot{\delta}_{i}=\frac{\partial \psi}{\partial T_{i}}, \quad \text { i.e. } \quad \dot{\delta}_{n}^{c r}=\frac{\partial \psi}{\partial T_{n}} \quad \text { and } \quad \dot{\delta}_{t}^{c r}=\frac{\partial \psi}{\partial T_{t}}
$$

where $T_{e}$ is an effective traction which is a homogeneous function of degree 1 in $\left(T_{n}, T_{t}\right)$, and which is also a function of the current damaged state. Cocks [35] further demonstrates that surfaces of constant $T_{e}$ for increasing values of $m$ nest inside each other with the surface for $m=1$ forming the outer surface and that for $m \rightarrow \infty$ forming the inner-most surface. Also, surfaces for large values of $m$ lie close to that for $m \rightarrow \infty$, which is equivalent to a perfectly plastic material with yield strength equal to $\sigma_{0}$. Thus for the materials of interest here, for which $m$ is typically greater than 5 , we can provide a good estimate of $T_{e}$ by performing an upper bound limit load calculation for a perfectly plastic material using the mechanism of Eq. (4). This limit load problem has been solved by Yalcinkaya and Cocks [22] who demonstrate that at the limit condition

$$
T_{e}-\sigma_{0}=0
$$

where

$$
T_{e}=\left[\frac{T_{n}^{2}}{(1-f)^{2}+(\ln f)^{2} / 3}+\frac{3 T_{t}^{2}}{(1-f)^{2}}\right]^{1 / 2}
$$

where $f$ is the cavity area fraction. Substituting the resulting expression for $T_{e}$ in the potential of (7) gives

$$
\psi=\frac{1}{m+1} \frac{\dot{\delta}_{0}}{\sigma_{0}^{m}}\left[\frac{T_{n}{ }^{2}}{(1-f)^{2}+(\ln f)^{2} / 3}+\frac{3 T_{t}^{2}}{(1-f)^{2}}\right]^{(m+1) / 2}
$$

Thus the normal and tangential creep separation rate $\dot{\delta}_{n}^{c r}, \dot{\delta}_{t}^{c r}$ can be given by

$$
\begin{aligned}
& \dot{\delta}_{n}^{c r}=\frac{\partial \psi}{\partial T_{n}}=\dot{\delta}_{0}\left(\frac{T_{e}}{\sigma_{0}}\right)^{m} \frac{\partial T_{e}}{\partial T_{n}} \\
& \dot{\delta}_{t}^{c r}=\frac{\partial \psi}{\partial T_{t}}=\dot{\delta}_{0}\left(\frac{T_{e}}{\sigma_{0}}\right)^{m} \frac{\partial T_{e}}{\partial T_{t}}
\end{aligned}
$$

where 


$$
\begin{aligned}
& \frac{\partial T_{e}}{\partial T_{n}}=\left[\frac{T_{n}^{2}}{(1-f)^{2}+(\ln f)^{2} / 3}+\frac{3 T_{t}^{2}}{(1-f)^{2}}\right]^{-1 / 2} \cdot \frac{T_{n}}{(1-f)^{2}+(\ln f)^{2} / 3} \\
& \frac{\partial T_{e}}{\partial T_{t}}=\left[\frac{T_{n}^{2}}{(1-f)^{2}+(\ln f)^{2} / 3}+\frac{3 T_{t}^{2}}{(1-f)^{2}}\right]^{-1 / 2} \cdot \frac{3 T_{t}}{(1-f)^{2}}
\end{aligned}
$$

And the evolution of the total separation can be expressed as follows (with elasticity incorporated [8]):

$$
\begin{aligned}
& \dot{\delta}_{n}=\frac{c \dot{T}_{n}}{1-f}+\dot{\delta}_{n}^{c r}=\frac{c \dot{T}_{n}}{1-f}+\dot{\delta}_{0}\left(\frac{T_{e}}{\sigma_{0}}\right)^{m} \frac{\partial T_{e}}{\partial T_{n}} \\
& \dot{\delta}_{t}=\frac{c \dot{T}_{t}}{1-f}+\dot{\delta}_{t}^{c r}=\frac{c \dot{T}_{t}}{1-f}+\dot{\delta}_{0}\left(\frac{T_{e}}{\sigma_{0}}\right)^{m} \frac{\partial T_{e}}{\partial T_{t}}
\end{aligned}
$$

where $c$ depicts the elastic constant. Further, note that under shear loading, pores become more crack like and elongate in the direction of shear [22]. Following the geometry in Fig. 4, a new evolution law for the physical damage variables, i.e. the cavity area fraction $f$ and cell height $h$ can be derived, considering that shear deformation does not change the volume [22].

$$
\begin{aligned}
& 4 \pi a^{2} h=\pi\left(2 a+\dot{\delta}_{t}^{c r} \Delta t\right)^{2}(h-\dot{h} \Delta t) \\
& \dot{f}=\frac{2 a}{l} \cdot \frac{\dot{a}}{l}=\frac{\sqrt{f} \dot{\delta}_{t}^{c r}}{l}
\end{aligned}
$$

Therefore

$$
\begin{aligned}
& \dot{f}=\frac{\dot{\delta}_{n}^{c r}}{h}(1-f)+\sqrt{f} \frac{\dot{\delta}_{t}^{c r}}{l} \\
& \dot{h}=\dot{\delta}_{n}^{c r}-\frac{h}{a} \dot{\delta}_{t}^{c r}=\dot{\delta}_{n}^{c r}-\frac{h}{l \sqrt{f}} \dot{\delta}_{t}^{c r}
\end{aligned}
$$

It can be seen that both normal and tangential tractions and separations are coupled in Eqs. (14) and (16). In addition, the damage accumulation in the interface zone by cavitation is still a displacement-based ductility exhaustion criterion [36-41] but is no longer a sole function of the normal creep separation as used in our previous work [8].
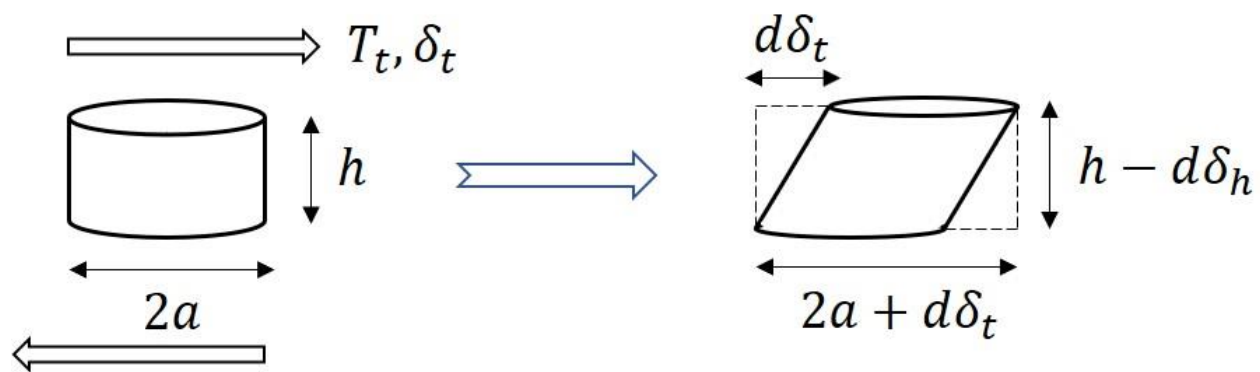

Fig. 4 Geometry change of pores under shear loading

\section{Finite element framework}

3.1. Dissimilar metal welded P91/Inco82 two-dimensional plate with different weld angles 
Here we take a simple two-dimensional plate model of a P91/Inco82 DMW to explore how the physical damage zone model described above can capture the effect of weld angle on creep rupture at the interface subject to remote uniaxial loading at $550^{\circ} \mathrm{C}$. The plane strain condition is adopted as the simulated creep rupture life with a $90^{\circ}$ weld angle (loading direction perpendicular to the interface) has been found to be closer to that of the actual axisymmetric cylinder geometry than the plane stress condition [8]. The established plate model of a P91/Inco82 DMW is shown in Fig. 5(a), with the same dimensions as in our previous work [8]. For the boundary conditions, the horizontal movement of the left side is constrained, and the vertical movement of the two corner nodes at the bottom is constrained. Each node of the four-node linear interface element has two degrees of freedom (normal and tangential), two displacement components $(u)$ and corresponding increments $(\Delta u)$. This is coded as a User-defined Element Library Subroutine (UEL) in the commercial finite element code ABAQUS.

Five weld angles $\theta$ are selected here, respectively $90^{\circ}, 75^{\circ}, 60^{\circ}, 45^{\circ}$ and $30^{\circ}$. We first calibrate the parameters in the physical model against the enriched interface creep rupture data for a $90^{\circ}$ weld angle (Fig. 2) and then use the calibrated model to predict the interface creep rupture life with other weld angles. The finite element meshes adjacent to the interface are shown in Fig. 5(b), taking the $45^{\circ}$ weld angle as an example, with 200 equally distributed interface elements and refined elements in the HAZ and Inconel towards the interface to provide the finest elements adjacent to the interface zone [8,21]. A mesh sensitivity study has been carried out elsewhere [21], with different numbers of interface elements equally distributed along the interface zone. Both the creep crack initiation time and creep crack growth rate have been found to decrease with decreasing mesh size along the interface, but the sensitivity becomes negligible as the mesh size decreases to $30 \mu \mathrm{m}$ and below. Therefore, use of 200 interface elements ensures that the computed rupture life is reasonable.

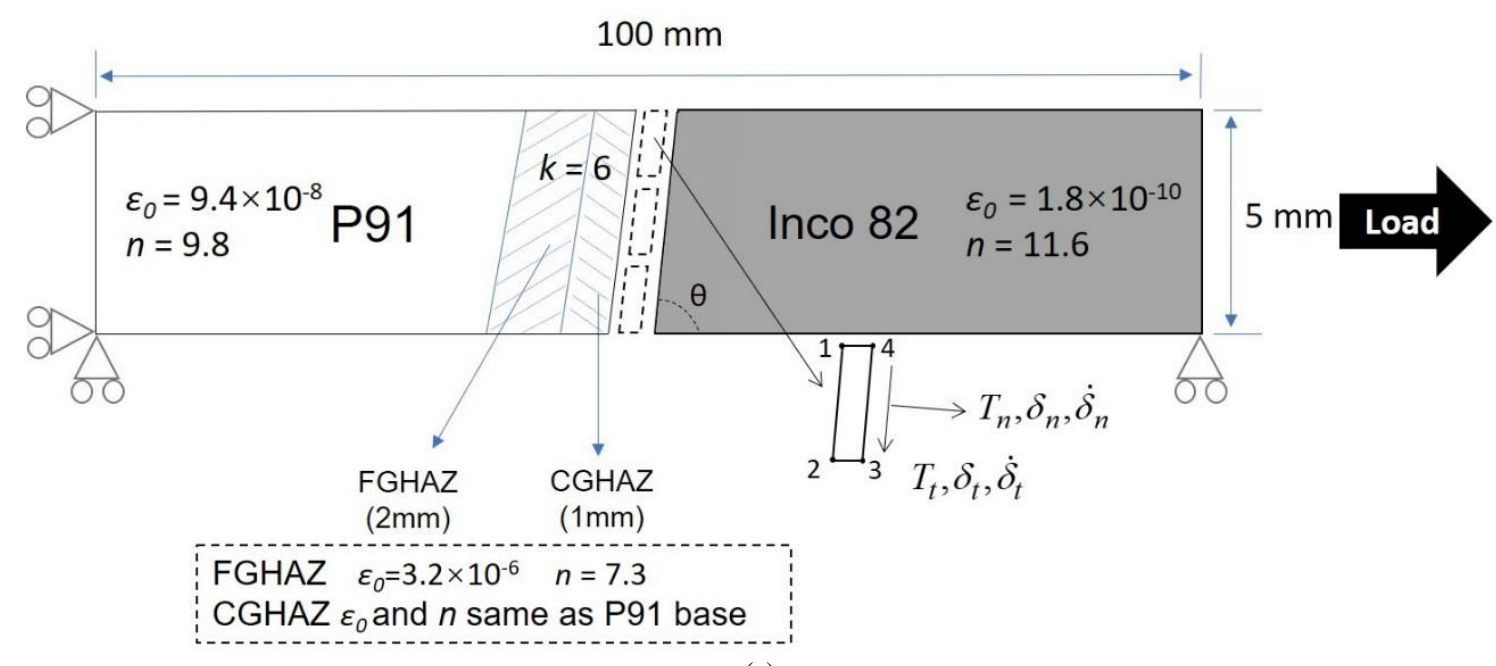

(a)

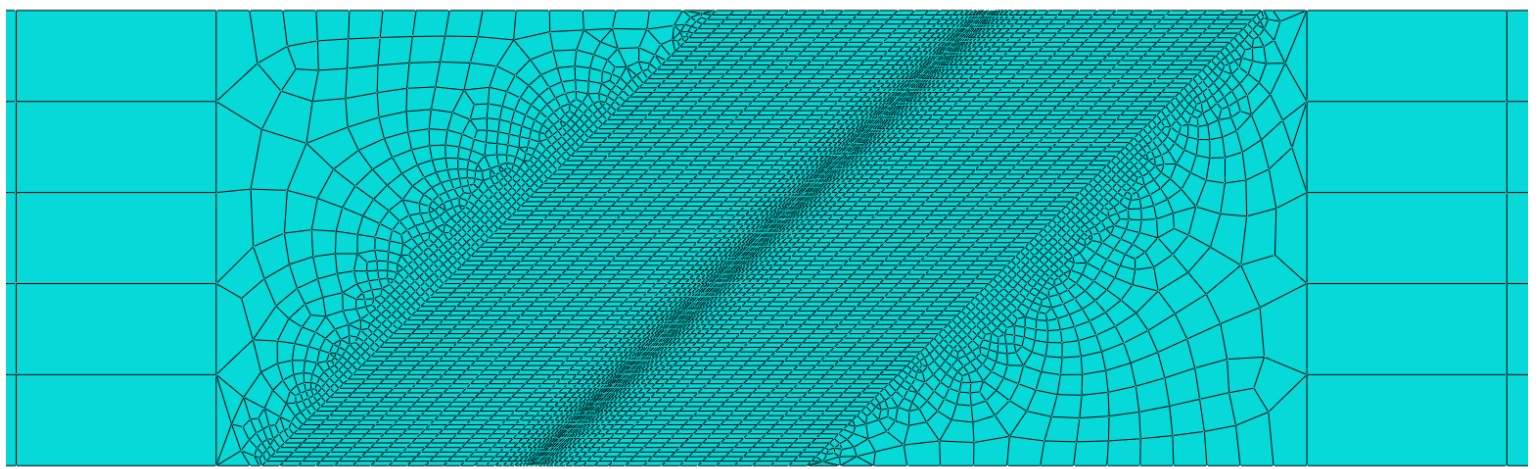

(b)

Fig. 5. (a) Schematic of two-dimensional plate model of P91/Inco82 DMW system subject to uniaxial creep loading at $550^{\circ} \mathrm{C}$. FGHAZ and CGHAZ are created as layers parallel to the interface and with a weld angle $\theta$ with respect to the direction of the applied load. The interface is modelled as a zone filled with four-node linear interface elements, each node having two degrees of freedom (normal and tangential). (b) Refined meshes in the $\mathrm{HAZ}$ towards the interface (taking a $45^{\circ}$ weld angle as an example). 


\subsection{Computational scheme}

Two-dimensional plane strain (CPE4) elements are used for the continuum elements of the P91 base metal, Inco82 filler metal and P91 CG(FG)HAZ. Values of the material parameters in the power-law creep relationship (Eq. 1) for P91 base metal and Inco82 filler metal, and power-law with softening (Eq. 2) for P91 FG(CG)HAZ remain the same as in our previous work and are not shown here [8]. The CREEP subroutine in ABAQUS has been used to implement the HAZ softening and the cavity nucleation models, where the number ratio of cavities $\left(N / N_{c}\right)$ is stored as a solution dependent variable (SDV).

The simulation consists of two steps: (1) STATIC elastic loading and heating from $20^{\circ} \mathrm{C}$ to $550^{\circ} \mathrm{C}$; (2) VISCO creep. Convergence in both the solution of the stress and strain in the global continuum elements and of tractions and separations in the local interface elements must be achieved. At the beginning of each time increment $(\Delta t)$ during the time-dependent VISCO creep step, ABAQUS provides UEL with the solutions of the normal and tangential tractions and creep separations $\left(T_{n}, T_{t}, \delta_{n}^{c r}, \delta_{t}^{c r}\right)$ from the last increment, as well as the current solution for the increase in total separation $\left(\Delta \delta_{n}, \Delta \delta_{t}\right)$ during the current increment as determined from the increment in nodal displacements $(\Delta u)$. A fourth-order Jacobian matrix $\partial T / \partial \delta$ is derived from four independent equations to calculate $\Delta T_{n}, \Delta T_{t} \Delta \delta_{n}^{c r}, \Delta \delta_{t}^{c r}$ over the time increment $\Delta t$ and the values at the end of the increment $\left(T_{n}+\Delta T_{n}, T_{t}+\Delta T_{t}\right.$, $\delta_{n}^{c r}+\Delta \delta_{n}^{c r}, \delta_{t}^{c r}+\Delta \delta_{t}^{c r}$ ) are determined through a Newton-Raphson iterative scheme (see Appendix). These are then used to calculate $\Delta f$ and $\Delta h$ using Eq. (16). Once $f$ reaches a critical value $f_{c}$, the interface element fails. The overall time to failure has been approximated by the time at which the entire simulation is allowed to terminate, which corresponds to a small time increment of $1 \times 10^{-8} \mathrm{~h}$ to achieve convergence.

\section{Simulation of mix-mode creep rupture at interface of a P91/Inco82 DMW system}

\subsection{Interface zone model calibration}

According to the reported data in Fig. 2, we have selected three remotely applied loads (200 MPa, $175 \mathrm{MPa}$ and $160 \mathrm{MPa}$ ) to calibrate the parameters for the physical cavity growth interface zone model when the weld angle is $90^{\circ}$ and subsequently selected two loads (177 MPa and $160 \mathrm{MPa}$ ) to predict the interface creep rupture life of the other four weld angles. Firstly, we reduce the number of free parameters by keeping the elastic constant $c$, reference stress $\sigma_{0}$ and damage zone exponent $m$ in Eq. (14) the same as those used in our previous work for a P91/Inco82 DMW system [8, 21]. Secondly, the simulated total interface creep rupture life has been found to be insensitive to the initial volume fraction of voids $f_{0}$ (e.g. in the range between 0.0001 and 0.01 ), thus it is simply set to 0.01 . Thirdly, the relationship between the initial height $\left(h_{0}\right)$ and width $\left(l_{0}\right)$ of the unit cell must satisfy $h_{0}<<l_{0}$, in terms of the geometrical constraint of the interface element depicted in Fig. 5. However, it should be noted that $h_{0}$ and $l_{0}$ are not identical to the geometrical dimensions of the interface element in the mesh shown in Fig. 5 but are rather characteristic geometrical length-scale parameters requiring further fitting. In addition, note that the reference separation rate $\dot{\delta}_{0}$ is a material length-scale parameter related to the reference strain rate by $\dot{\delta}_{0}=\dot{h}_{0}=\dot{\varepsilon}_{0} h$. Fitting must thus ensure the ratio $\dot{\delta}_{0} / h_{0}$ has an appropriate order of magnitude to avoid the interface being too stiff or too soft during the VISCO creep step. The last fitting parameter is the critical volume fraction of voids $f_{c}$, which determines when an interface element fails. With the above constraints, the parameters are adjusted in an ABAQUS simulation until the simulated creep rupture life of a $90^{\circ}$ weld matches the data. The values of all the parameters are shown in Table 1.

Table 1 Value of the parameters in the physical cavity growth model for P91/Inco82 DMW system

\begin{tabular}{llllllll}
\hline$c(\mathrm{~mm} / \mathrm{MPa})$ & $\sigma 0(\mathrm{MPa})$ & $m$ & $\delta_{0}\left(\mathrm{~h}^{-1}\right)$ & $h_{0}(\mathrm{~mm})$ & $l_{0}(\mathrm{~mm})$ & $f_{0}$ & $f_{c}$ \\
\hline
\end{tabular}


Figure 6 presents the reported interface creep rupture data of $90^{\circ}$ and $45^{\circ}$ welds, as well as the fitted simulation result of the $90^{\circ}$ weld and predicted results of the other four weld angles. Within the interested stress range, the interface creep rupture life of $75^{\circ}$, $60^{\circ}$ and $45^{\circ}$ welds are found to be shorter than that for the $90^{\circ}$ weld, whereas the $30^{\circ}$ weld is found to exhibit a longer life. A more detailed comparison between different weld angles is presented in the following section. Results with different weld angles seem to exhibit a similar slope between the applied stress and logarithmic rupture life. Further, it is seen that the predicted result of the $45^{\circ}$ weld agrees with the trend, although it predicts a longer life at $177 \mathrm{MPa}$ and a shorter life at $160 \mathrm{MPa}$ by approximately $30 \%$.

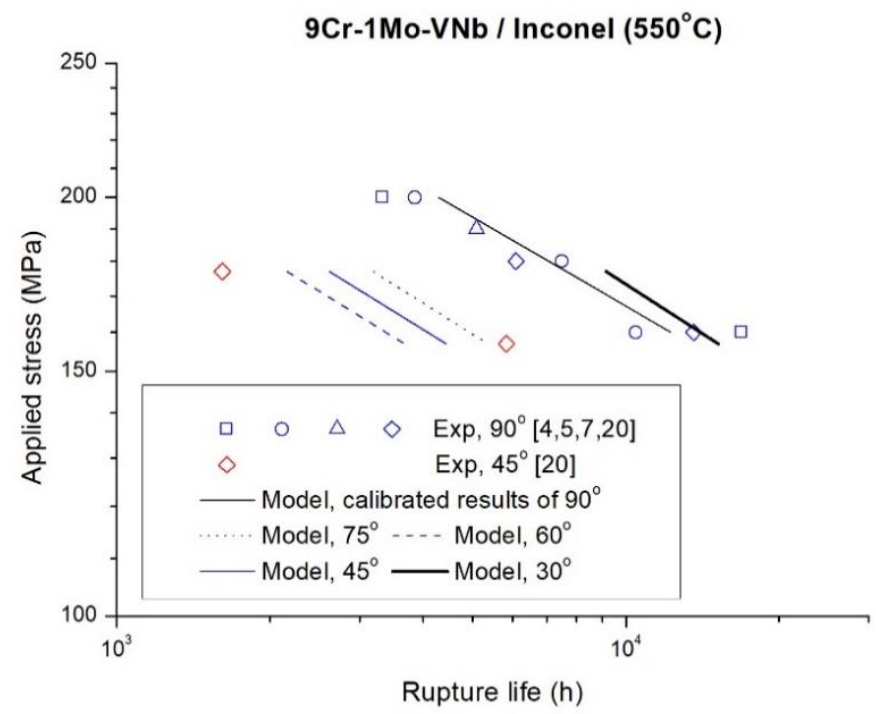

Fig. 6 Experimental and simulated (plain strain model) creep rupture life of a P91/Inco82 DMW system which experience interface failure at 550 ${ }^{\circ} \mathrm{C}$. Open symbols represent experimental data $\left(90^{\circ}\right.$ and $45^{\circ}$ weld interface $\left.[4,5,20]\right)$ and lines are model calibrated $\left(90^{\circ}\right)$ or predicted (other weld angles) results.

Taking the $45^{\circ}$ weld interface at $160 \mathrm{MPa}$ as an example, crack initiation and propagation can be visualized by tracking the evolution of the component of stress that is normal to the weld interface as presented in Fig. 7. A uniform scale is used in the legend (0-100 MPa) for comparison. Patterns at other applied loads and weld angles are similar. Black crosses in these figures refer to the interface elements. The initial concentration is observed at the free edge (Fig. 7a) where the interface meets the free outside surface, which is a direct reflection of the mismatch in thermal and elastic properties between the materials on the two sides of the interface. The stress concentration gradually relaxes as a result of creep and damage accumulation (Fig. 7b). Crack initiation occurs at the position of initial stress concentration (Fig. 7c) once the damage $(f)$ reaches the critical value $\left(f_{c}\right)$, followed by fast crack propagation towards the centre, terminating in creep rupture (Fig. 7d). The stress concentration recurs during crack initiation and propagation, close to the crack tip (Fig. 7c \& d). 

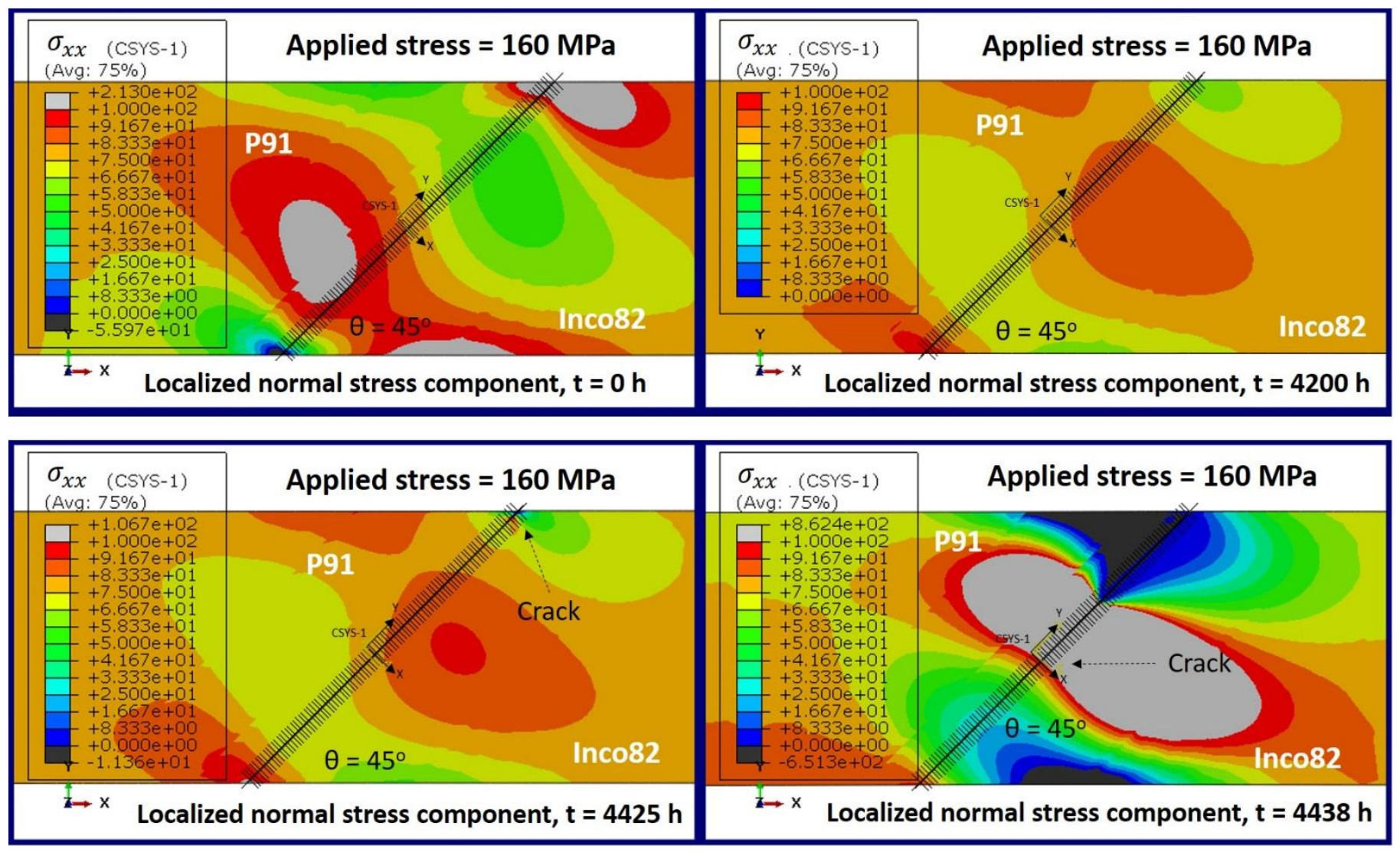

Fig. 7 Distribution of the component of stress normal to the $45^{\circ}$ weld interface of P91/Inco82 DMW system subjected to a remote applied stress of $160 \mathrm{MPa}$ at $550^{\circ} \mathrm{C}$ at different creep rupture stages: (a) before creep; (b) at intermediate stage with stress relaxation; (c) at crack initiation and (d) at crack propagation and final rupture. The black crosses depict the interface elements.

\subsection{Comparison between results of different weld angles}

Attention will now focus on the detailed comparison of the simulated results for the different interface weld angles. Firstly, from Fig. 6 at a given load within the interested range, the predicted creep rupture life is observed to exhibit a sequence such that $30^{\circ}>90^{\circ}>75^{\circ}>45^{\circ}>60^{\circ}$, indicating that a $60^{\circ}$ weld is the most detrimental and a $30^{\circ}$ weld is beneficial, compared with the standard $90^{\circ}$ weld. In mix-mode problems, these demonstrate the complexity in the combined effect of normal and tangential tractions on damage growth. Here we take a remote axial stress of $160 \mathrm{MPa}$ as an example to explore the underlying reason for this trend. The normal and shear components of stress (with respect to a coordinate system defined by the orientation of the weld interface) in the vicinity of the weld are shown in Fig. 8 for different weld angles $\left(75^{\circ}, 60^{\circ}, 45^{\circ}\right.$ and $\left.30^{\circ}\right)$ after about $3500 \mathrm{~h}$ creep. Both the scales of normal and shear components of stress have been uniformed (150-30 MPa for normal, 80-0 MPa for shear) for all the weld angles. From the contour, it is found that the average level of the normal stress component in the local coordinate system (shown in Fig. 8) near the weld interface decreases from $\sim 150 \mathrm{MPa}$ to $\sim 80 \mathrm{MPa}$ as the weld angle decreases from $75^{\circ}$ to $45^{\circ}$, while that of the shear stress component increases from $\sim 40 \mathrm{MPa}$ to $\sim 80 \mathrm{MPa}$. As the weld angle decreases below $45^{\circ}$, i.e. for $30^{\circ}$ weld, the average level of the normal stress component continues to decrease to $\sim 40 \mathrm{MPa}$, whereas that of the shear stress component reverses the trend and increases to $\sim 70 \mathrm{MPa}$, a similar level to that of $60^{\circ}$ weld. A representative stress value at the centre location of the interface (nearly equal on both sides) is provided in the figure, showing agreement with this trend. It should be noted that all these average stress levels are as expected that can be obtained by simply resolving the remotely applied stress into the defined local coordinate system. 


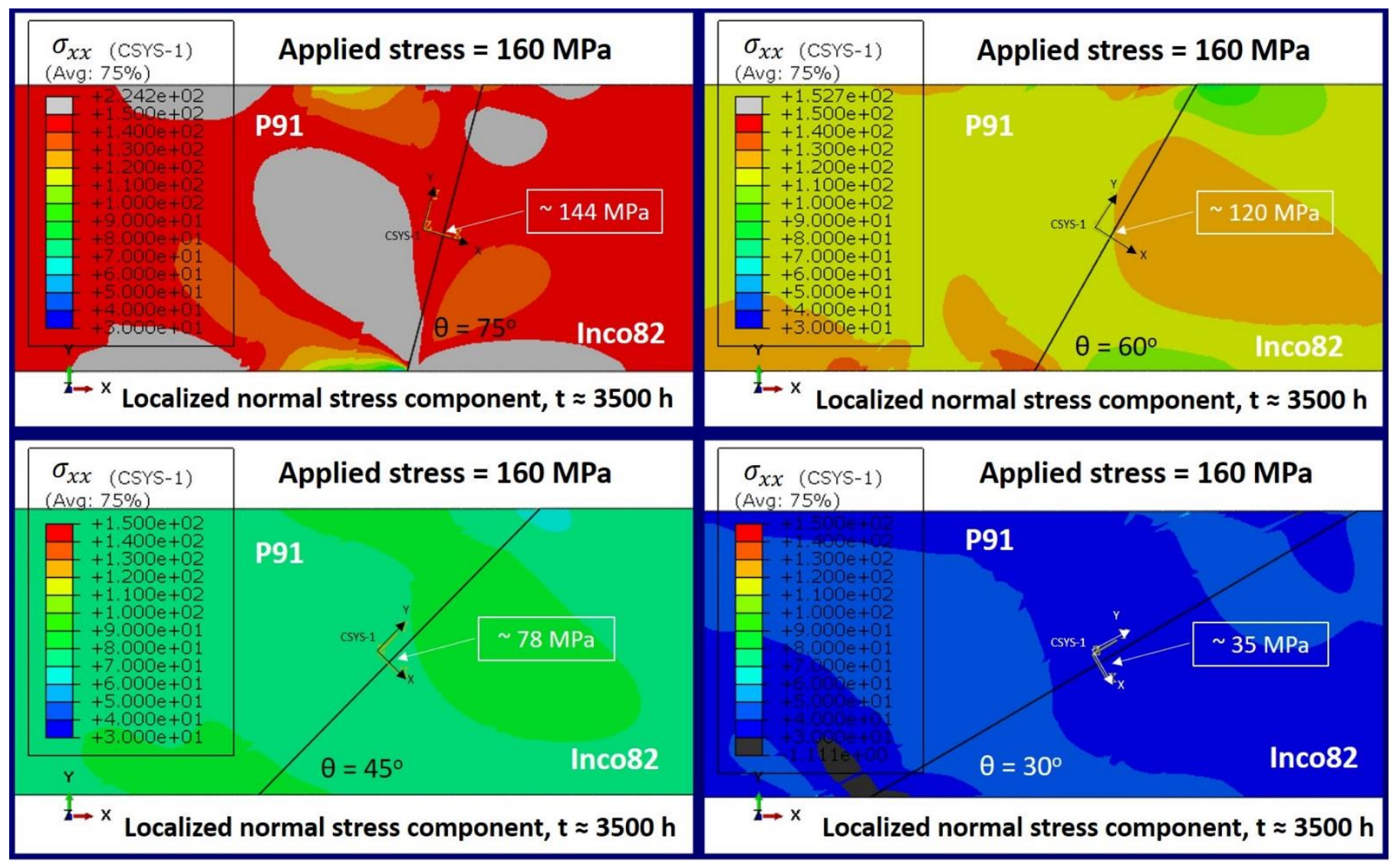

(a)

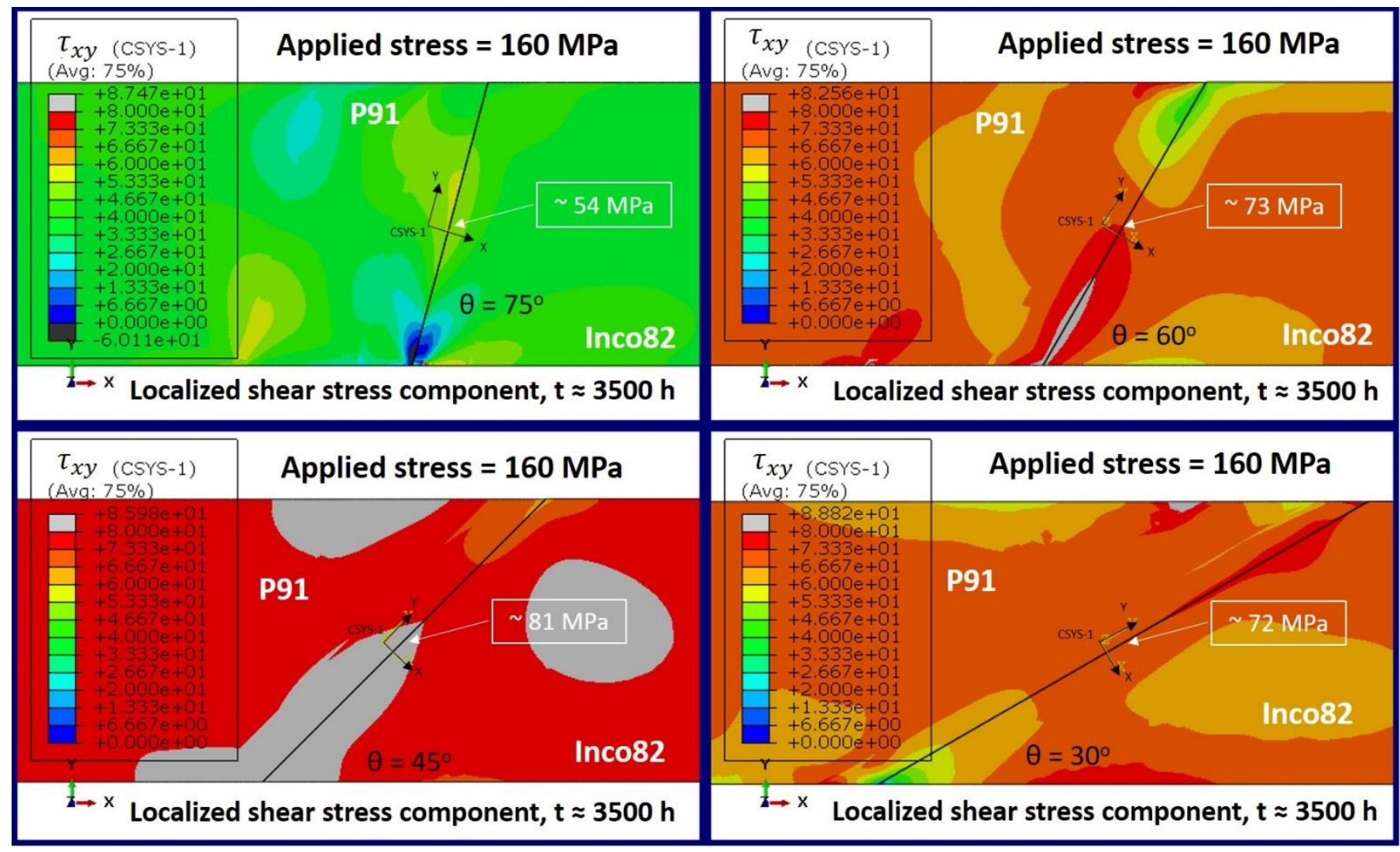

(b)

Fig. 8 Distribution of (a) normal (uniform scale 150-30 MPa) and (b) shear stress components (uniform scale 80-0 MPa) resolved along the plane of the weld interface of P91/Inco82 DMW system with different weld angles $\left(75^{\circ}, 60^{\circ}, 45^{\circ}\right.$ and $\left.30^{\circ}\right)$, subjected to a remote applied stress of $160 \mathrm{MPa}$ after a given period $(3500 \mathrm{~h})$ of creep at $550^{\circ} \mathrm{C}$. A representative stress value at the centre location of the interface is shown in each figure. 
The detailed evolution of the distributions of the tractions normal and tangential to the interface elements (local coordinate system) are shown in Fig. 9 for the $75^{\circ}, 60^{\circ}, 45^{\circ}$ and $30^{\circ}$ welds during creep at $550^{\circ} \mathrm{C}$ under an axial stress of $160 \mathrm{MPa}$. The distance has been normalised with respect to the length of the weld, with the origin at the bottom edge of the weld. Both tractions concentrate at the top edge at the beginning and relax during subsequent creep. Load is gradually transferred to the interior region towards the bottom edge. Note that the sign of the tangential traction at the bottom edge is found to change during creep. The representative stress location and value are marked in each figure. It can be clearly seen that, as the weld angle decreases, the decrease of the average normal traction is much greater than the increase of the average absolute tangential traction, similar to the trend shown in Fig. 8.

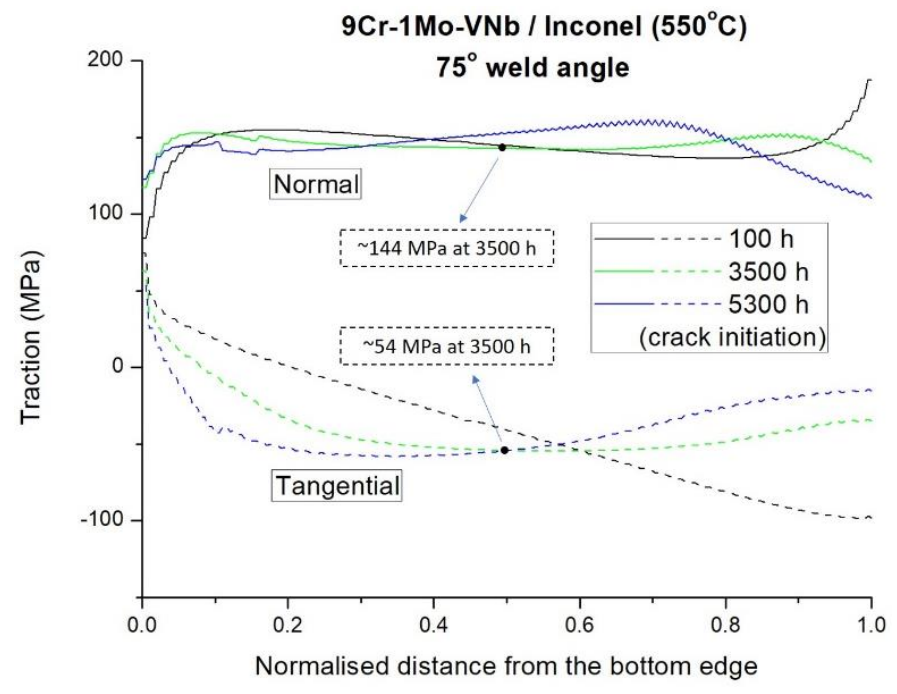

(a)

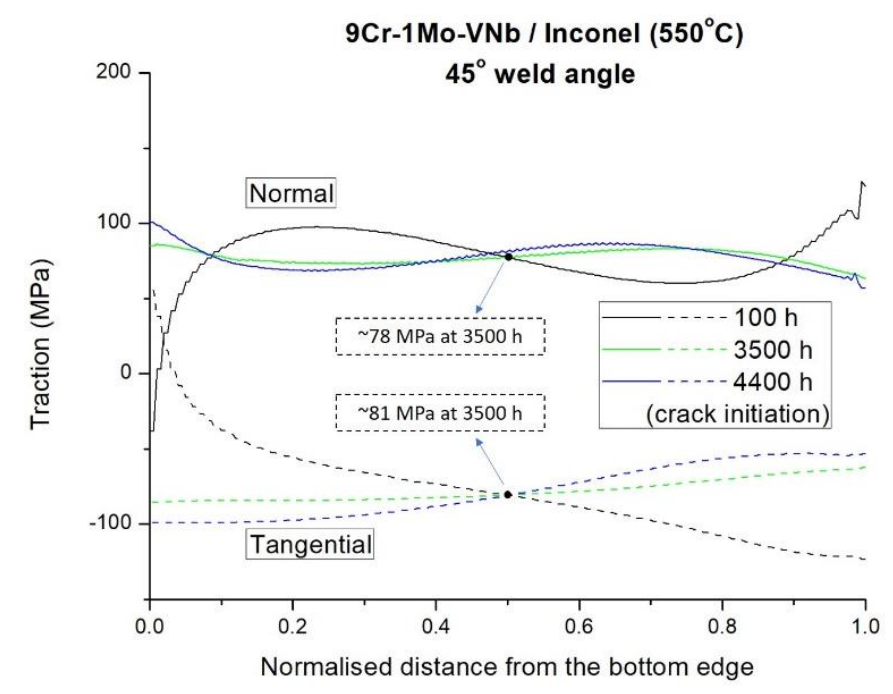

(c)

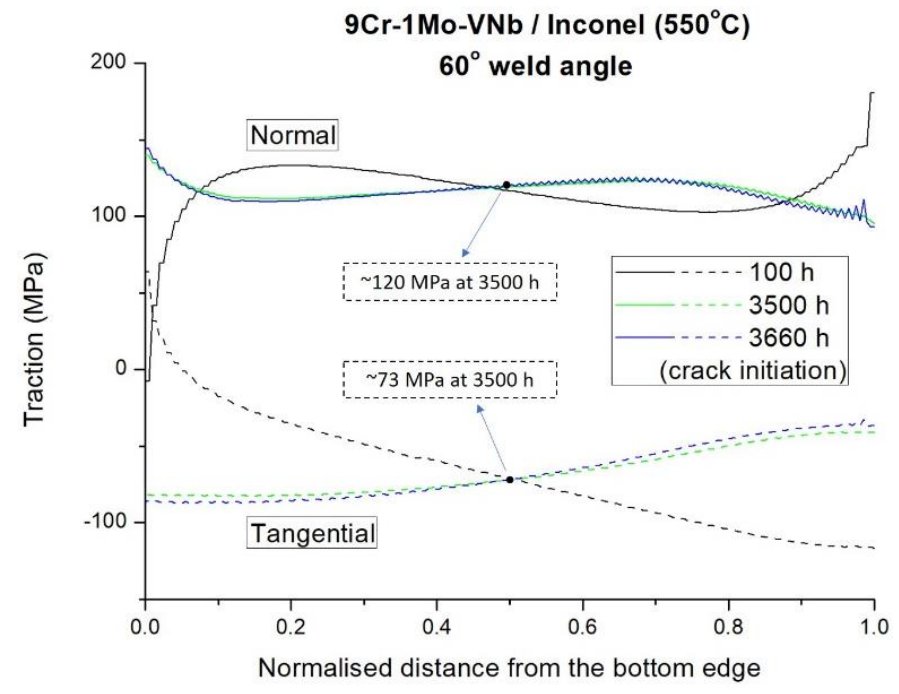

(b)

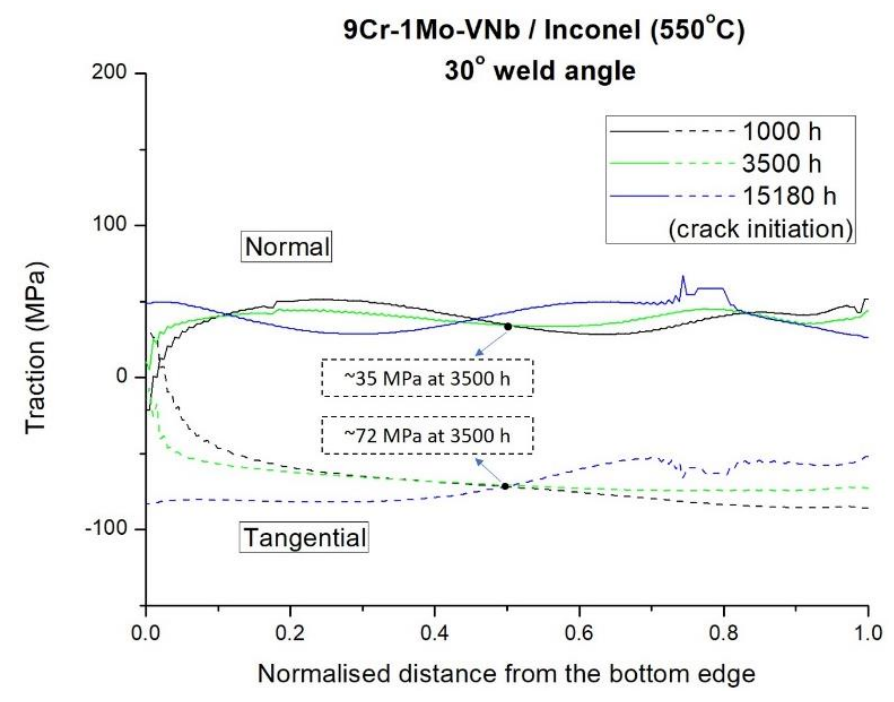

(d)

Fig. 9 Evolution of the distributions of the traction normal and tangential to the P91/Inco82 dissimilar interface with the weld angles of (a) $75^{\circ}$, (b) $60^{\circ}$, (c) $45^{\circ}$ and (d) $30^{\circ}$ during creep at $550^{\circ} \mathrm{C}$ subject to a remote load of $\mathbf{1 6 0} \mathbf{~ M P a}$.

The corresponding evolution of creep damage (normalised area fraction of cavities, i.e. $f / f_{c}$ with a range from 0 to 1 ) along the interface (normalised distance from the bottom edge in Fig. 5a) is illustrated in Fig. 10 for the four weld angles considered in Fig. 9. In all cases, the fastest damage accumulation occurs near the top edge, consistent with the initial stress concentration region. In addition, the damage accumulation in the interior region is found to become faster as the weld angle decreases, which is a direct consequence of the enhanced shear stress component shown in Fig. 9. When the weld angle is equal to or above $45^{\circ}$, a crack is found 
to initiate where the interface meets the free surface at the top edge. The weld with the shortest life, i.e. the $60^{\circ}$ weld, experiences not only an earlier crack initiation, but also a faster accumulation of damage along the entire length of the weld. However, for the $30^{\circ}$ weld, two cracks are found to initiate almost simultaneously, with the primary one in the interior region just beneath the top edge and the secondary one at the top edge.

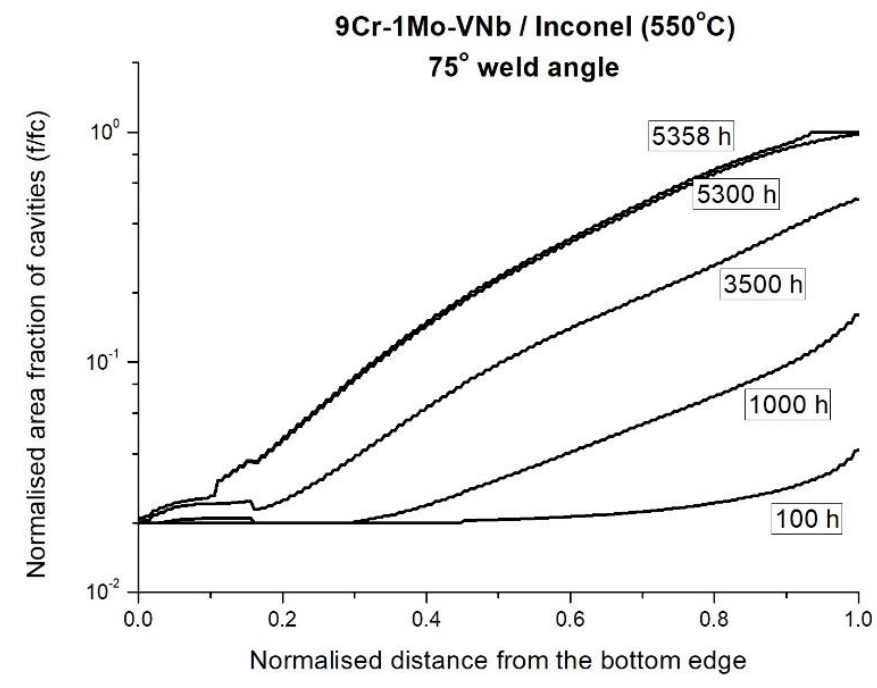

(a)

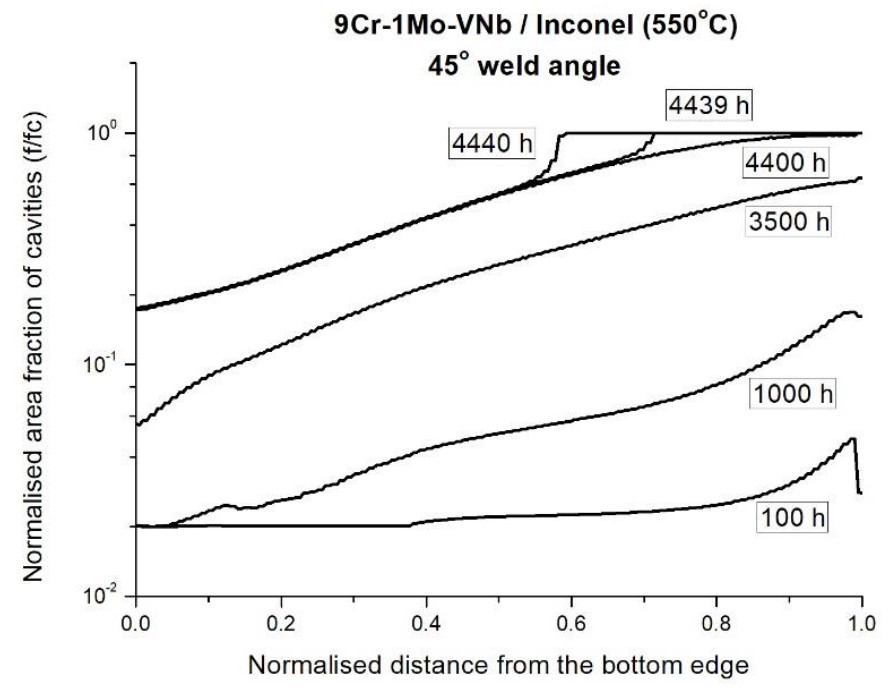

(c)

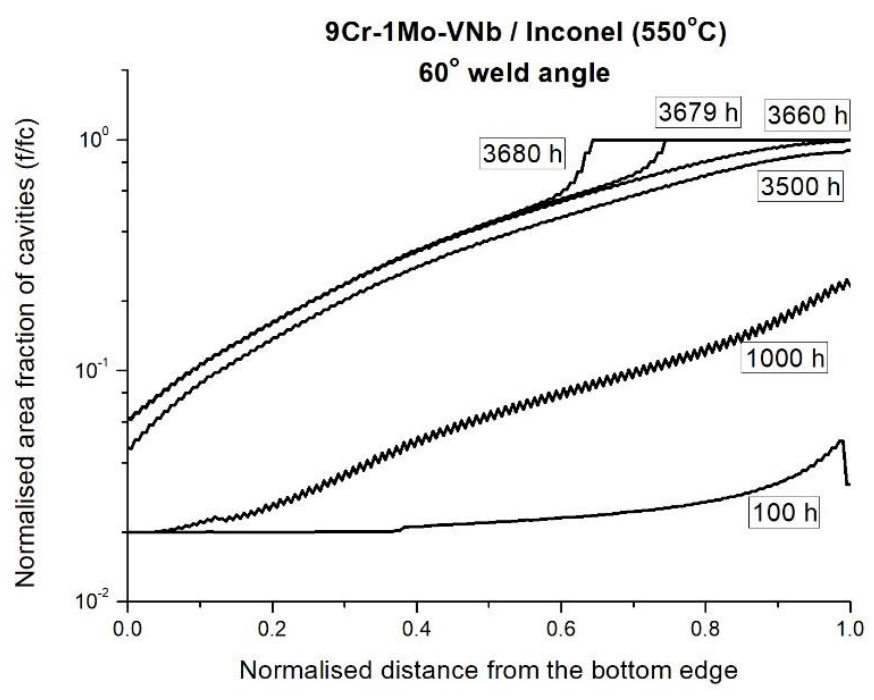

(b)

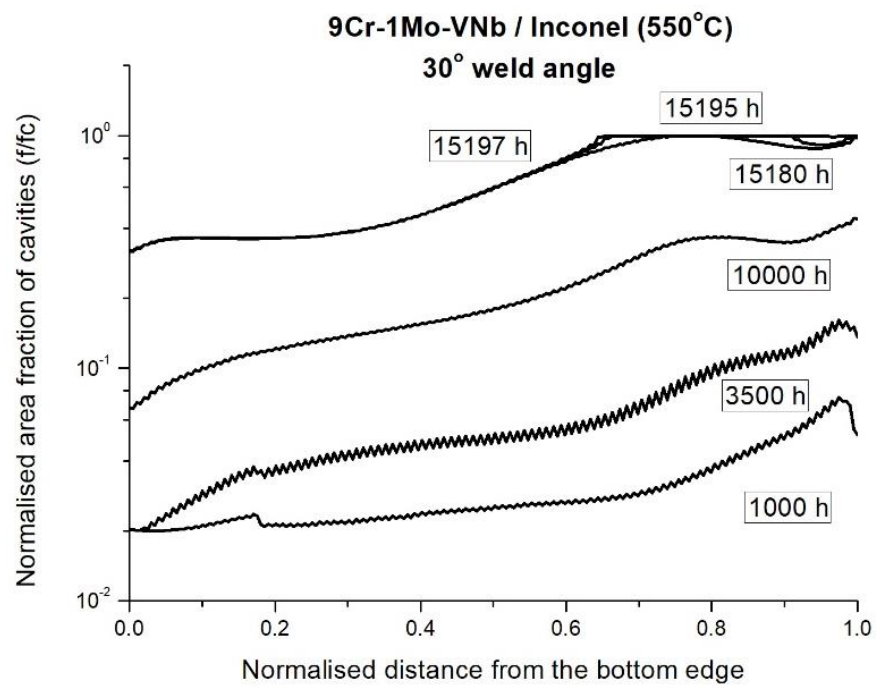

(d)

Fig. 10 Evolution of normalised damage accumulation $\left(f / f_{c}\right)$ along the P91/Inco82 dissimilar interface with the weld angles of (a) $75^{\circ}$, (b) $60^{\circ}$, (c) $45^{\circ}$ and (d) $30^{\circ}$ during creep at $550^{\circ} \mathrm{C}$ subject to a remote load of $160 \mathrm{MPa}$.

In order to provide some insight into the observed trend in life with weld angle, we undertake the following simplified analysis. First, assume that the tractions along the line of the weld are constant and we determine their magnitudes by simply resolving the applied stress normal and tangential to the line of the weld and assuming that they remain constant during creep and damage development, i.e. $T_{n}=150 \mathrm{MPa}, T_{t}=-40 \mathrm{MPa}$ for the $75^{\circ}$ weld, $T_{n}=120 \mathrm{MPa}, T_{t}=-70 \mathrm{MPa}$ for $60^{\circ}, T_{n}=80 \mathrm{MPa}, T_{t}=-80 \mathrm{MPa}$ for $45^{\circ}$, and $T_{n}=40 \mathrm{MPa}, T_{t}=-70 \mathrm{MPa}$ for the $30^{\circ}$ weld. Second, we select a range of area fraction of the cavities from $f_{0}$ to $f_{c}(0.01-$ 0.5, Table 1), and calculate $T_{e}$ from Eq. (10) and $\dot{\delta}_{n}^{c r}, \dot{\delta}_{t}^{c r}$ from Eq. (12) at each value of $f$. Then we substitute $\dot{\delta}_{n}^{c r}, \dot{\delta}_{t}^{c r}$ and $f$ into Eq. (16) to calculate $\dot{f}, \dot{h}$. A constant value of $h=0.005$ (Table 1 ) is used for simplicity. $\dot{f}$ is plotted against $f$ for the four weld angles of interest in Fig. 11(a), with the individual contribution of normal and tangential separation rate plotted in Fig. 11(b). The state at the original $90^{\circ}$ weld is also shown for a comparison, in which $T_{n}=160 \mathrm{MPa}, T_{t}=-30 \mathrm{MPa}$. The tangential contribution to the 
overall damage accumulation rate $\dot{f}$ is found to be smaller than from the normal separation rate. However, for the duration of a test, although the $90^{\circ}$ weld experiences the largest normal traction, the contribution of the tangential traction is much greater in other weld angles, resulting in a net effect such that the $60^{\circ}$ weld experiences the fastest damage growth rate, which has the shortest life. On the contrary, the slowest damage growth rate is observed for the $30^{\circ}$ weld (Fig. 11a), which has the longest life. This can be attributed to the very low magnitude of the normal traction, leading to a low magnitude of the effective traction and separation rate (Eq. 12), although the $30^{\circ}$ weld has the same tangential traction as the $60^{\circ}$ weld. Despite the fact that this simple model does not take into account the effect of the non-uniform stress state in the vicinity of the weld and how this redistributes during creep and damage development, it captures, and provides an explanation for the major trends observed in the more complete analysis.

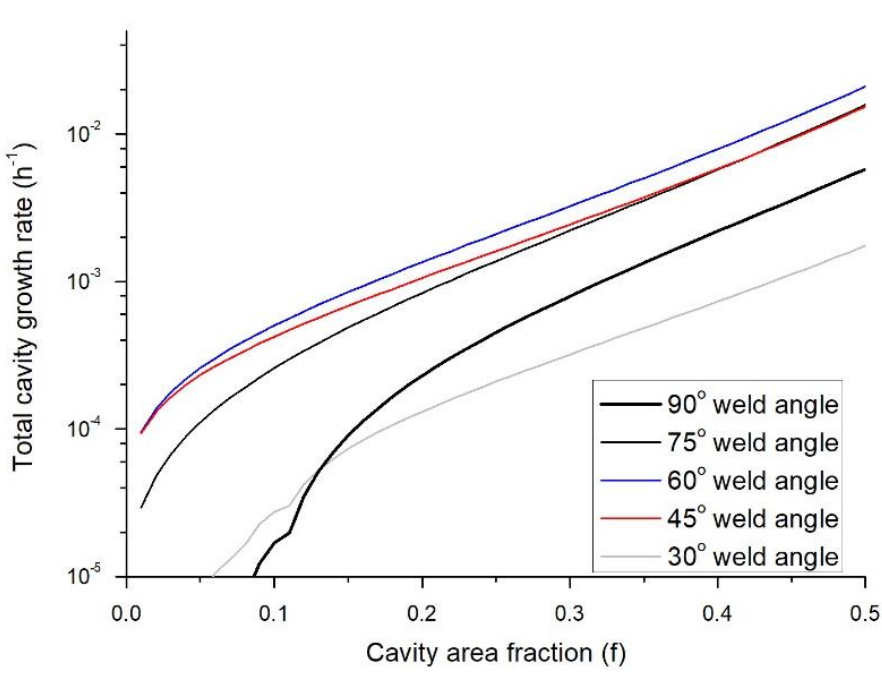

(a)

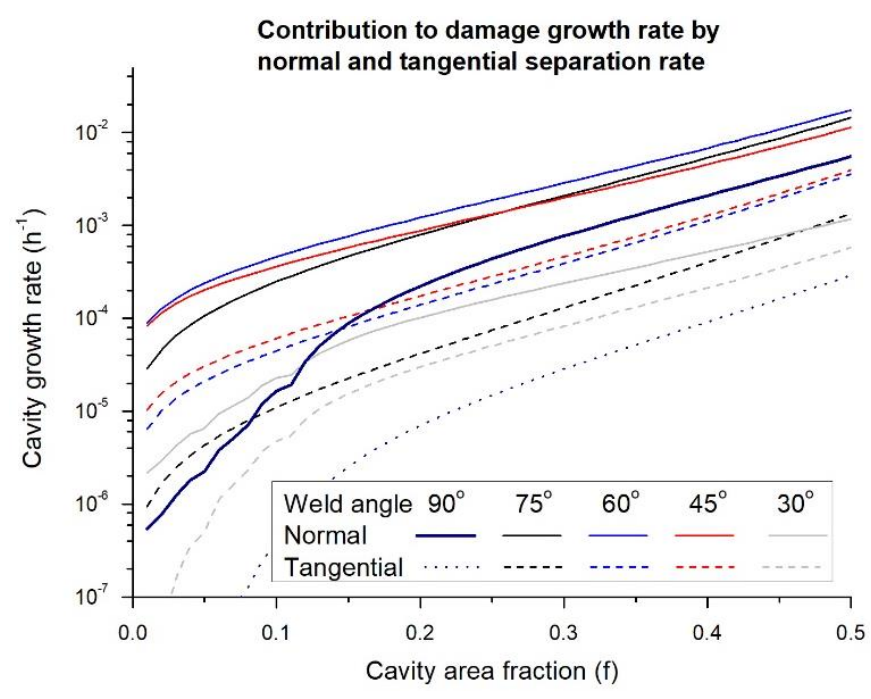

(b)

Fig. 11 Qualitative evaluation of the evolution of damage accumulation rate between the weld angles of $90^{\circ}, 75^{\circ}, 60^{\circ}, 45^{\circ}$ and $30^{\circ}$ as the cavity grows. (a) shows the overall damage growth rate and (b) separates the contribution from normal and tangential separation rate.

It is further noted from Fig. 10 that, similar to our previous result for a $90^{\circ}$ weld interface [8], the majority of life is taken by the crack initiation stage ( $98 \%)$, which can be largely attributed to the topology of the interface. The idealized flat interface only leads to a concentration of stress at, or close to, the outside surface, which is also the site for crack initiation. However, the real interface of practical components used in the experimental studies of Fig. 6 and in actual plant are wavy and irregular (i.e. with a mixture of different weld angles), causing a number of stress concentration positions and triggering earlier crack initiation at multiple sites and a more tortuous crack path. Here for research purposes, the significance of the idealized flat interface is that, firstly, the physical model, from the fundamental basis, successfully captures the contribution to the interface failure from the interaction between normal and tangential tractions and separations and its variation between different weld angles, and secondly, it can provide insight and guidance to practical welding processes for some beneficial weld angles (e.g. $30^{\circ}$ ) and/or avoidance of some detrimental weld angles (e.g. $\left.60^{\circ}\right)$.

Finally, the normalized cavity density $N / N_{c}$ (Eq. 3) in the HAZ of the P91/Inco82 DMW with $75^{\circ}, 60^{\circ}, 45^{\circ}$ and $30^{\circ}$ weld angles at the point of interface failure is presented in Fig. 12. A uniform scale is used in the legend of all the weld angles for comparison. It can be observed that, in all the cases, the normalized cavity density increases faster in the FGHAZ than in the CGHAZ, agreeing with the findings that the FGHAZ is the most favourable site for Type IV failure [29, 42, 43]. However, no concentration of cavities can be seen in CGHAZ up to failure at the interface, indicating that cracks are less likely to divert and propagate into the HAZ than in the $90^{\circ}$ weld angle considered in our previous work [8]. Therefore, the transition from a Type VII to a Type VI failure mode is less likely to occur at these weld angles within the interested temperature and stress range. 

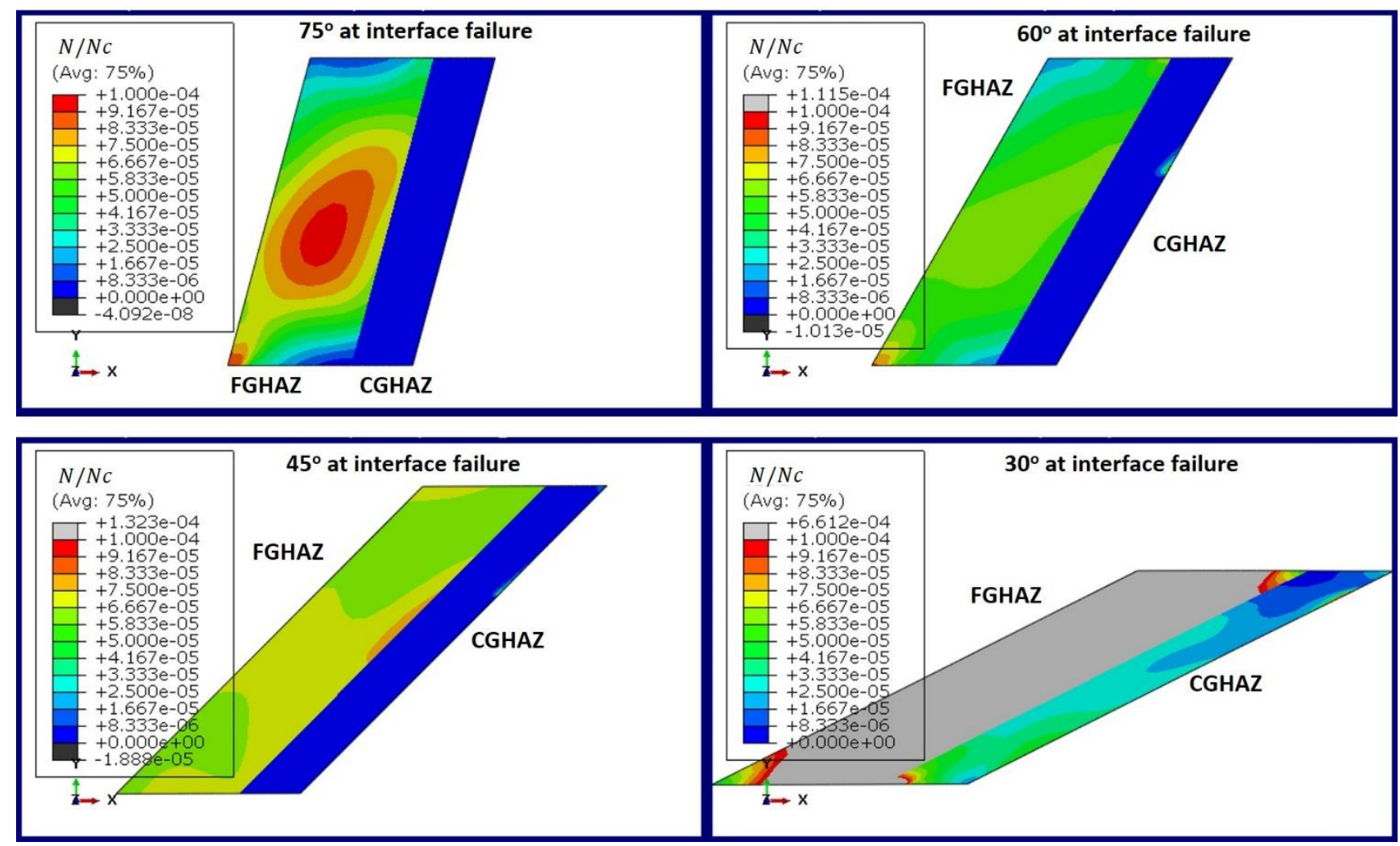

Fig. 12 Comparison of the magnitude of $N / N_{c}$ in $\mathrm{HAZ}$ of P91/Inco $82 \mathrm{DMW}$ system at interface failure between the weld angles of $75^{\circ}, 60^{\circ}, 45^{\circ}$ and $30^{\circ}$ subjected to a remote load of $160 \mathrm{MPa}$.

\section{Discussion}

The results and comparisons presented in section 4 highlights the significance of weld angle in the creep rupture life of the dissimilar welded component. Here we take the $45^{\circ}$ welded plate to explore the sensitivity of the rupture life to different boundary conditions and the presence of a pre-existing crack. Other potential sensitivities are also discussed.

\subsection{Case study 1 - sensitivity to boundary conditions}

Unlike the $90^{\circ}$ weld angle problem, the other weld angle problems considered in this study lack the geometrical symmetry about a line along the axis of the specimen. As a result of this, the response can be very sensitive to the details of the boundary condition applied to the sample; for example, the sample can bend and/or its ends need to rotate under a simple symmetric axial load, or under a fixed axial displacement a moment needs to be applied to prevent rotation - each of these scenarios will give rise to different stress states generated in the vicinity of the weld, that could potentially have an effect on damage development and the time to failure. The boundary condition used in the simulation above is illustrated in Fig. 5(a), typically with the vertical constraint on the node at the right corner of the bottom side, which prevents vertical displacement, but allows rotation of the end of the specimen. Here, we refer to this as boundary condition 1 (BC1) and consider two additional extreme boundary conditions, i.e. free and fully constrained boundary conditions (Fig. 13a), where for the free condition (BC2), the vertical constraint of the node at the free end in BC1 is removed, while for the fully constrained condition (BC3), the vertical displacement and rotation of half the length of the Inco82 is constrained. The length of all the DMWs analysed are the same as shown in Fig 5(a). Three remotely applied loads (177MPa, $160 \mathrm{MPa}$ and $120 \mathrm{MPa}$ ) are considered for comparison of the different boundary conditions. All the parameters and computational procedures remain the same in all cases as before. 
Boundary condition (BC) 2

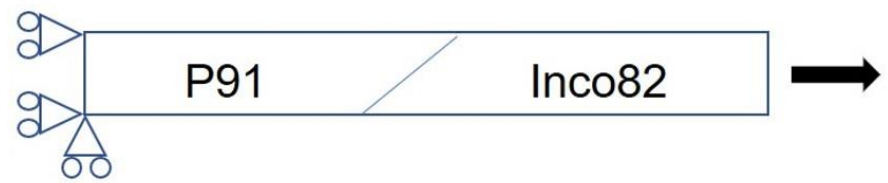

\section{Boundary condition (BC) 3}

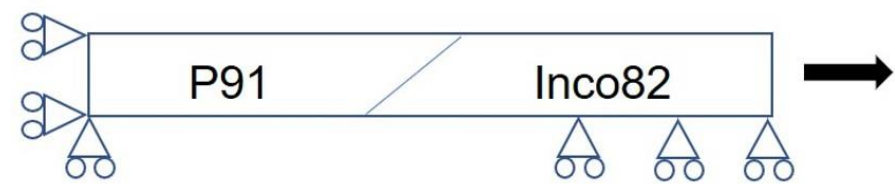

(a)
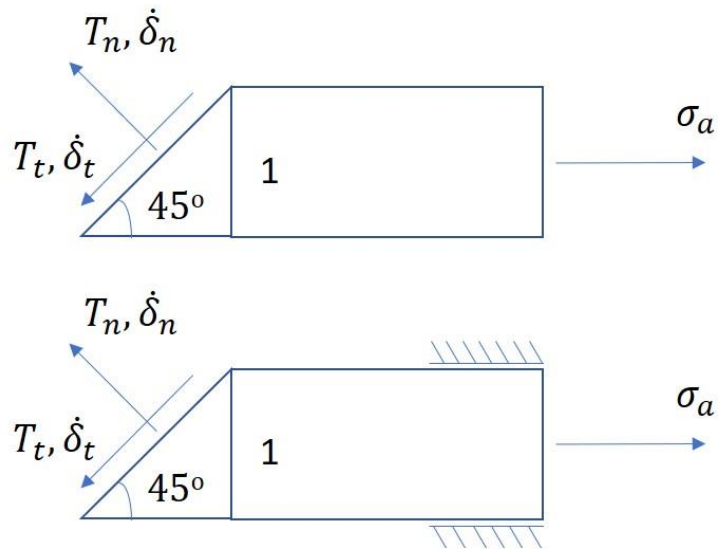

(b)

Fig. 13 (a) Uniaxial creep loading of a plate with $45^{\circ}$ weld angle interface, subject to free boundary (BC2) or fully constrained boundary (BC3). (b) A simple schematic showing the two boundary conditions, $\sigma_{\mathrm{a}}$ is the remote applied stress and the thickness of the problem is schematically normalised as 1 .

Table 2 presents and compares the simulated total rupture life at different applied loads and boundary conditions, as well as the percentage change relative to the original $\mathrm{BC} 1$. In general, it is found that the rupture life is not sensitive to different boundary conditions for the conditions considered in these simulations. For the current choice of parameters, the amount of deformation arising from growth of the damage at the interface is much less than that arising from deformation of P91 and Inco82. Under these conditions the deformation at the interface is readily accommodated by deformation and bending of the material either side of the interface - the amount of bending required is however small and the vertical forces generated at the supports in order to generate the required bending moments is negligible compared to the imposed axial force. A much shorter overall length and/or a more compliant interface is required to produce a noticeable effect. We can examine the significance of these effects by exploring the limiting situation where the material either side of the interface is rigid. The normal and tangential displacements, and therefore the tractions, are uniform along the interface. The rate of deformation in the interface, and therefore the rate of damage development, is largely determined by the effective traction $T_{e}$ defined in Eq. (10). For the free boundary condition of BC2 it can be readily shown that $T_{n}=T_{t}=\sigma_{a} / 2$ and therefore Eq. (10) gives

$$
T_{e}^{B C 2}=\frac{\sqrt{3}}{2} \frac{\sigma_{a}}{f_{t}^{1 / 2}}\left(1+\frac{f_{t}}{3 f_{n}}\right)^{1 / 2}
$$

where $f_{n}=(1-f)^{2}+(\ln f)^{2} / 3$ and $f_{t}=(1-f)^{2}$. For the constrained situation of BC3 axial equilibrium gives $\sigma_{a}=T_{n}+T_{t}$, while the constraint requires $\dot{\delta}_{n}=\dot{\delta}_{t}$. Equating Eq. (13) then gives a relationship between $T_{t}$ and $T_{n}$ in terms of $f_{t}$ and $f_{n}$. When combined with the axial equilibrium equation, this allows $T_{t}$ and $T_{n}$ to be expressed as functions of $\sigma_{a}, f_{t}$ and $f_{n}$. The resulting value of $T_{e}$ is then determined by substituting these expressions into Eq. (10):

$$
T_{e}^{B C 3}=\frac{\sigma_{a}}{f_{n}^{1 / 2}\left(1+f_{t} / 3 f_{n}\right)}\left(1+\frac{f_{t}}{3 f_{n}}\right)^{1 / 2}
$$

Then $\frac{T_{e}^{B C 2}}{T_{e}^{B C 3}}=\frac{1}{2}\left[\left(\frac{f_{t}}{3 f_{n}}\right)^{1 / 2}+\left(\frac{3 f_{n}}{f_{t}}\right)^{1 / 2}\right]$, which has a minimum value of 1 when the argument in the inner brackets is equal to 1. Thus

$$
T_{e}^{B C 2}>T_{e}^{B C 3}
$$


Note the use of the inequality, since the condition $f_{t}=3 f_{n}$ is never achieved. Therefore the effective traction for the unconstrained condition is always greater than for the equivalent constrained problem, meaning that the damage grows faster when deformation is unconstrained. This implies that constraining the deformation can enhance the life, but this is only achieved when deformation resulting from the growth of damage is significant and dominates the overall response. As deformation of the matrix either side of the interface becomes more significant, the effect of the constraint is reduced. The results of Table 2, suggest that there could still be a small effect of the constraint for the conditions employed in the computational simulations, since the life for BC3 is slightly greater than that for $\mathrm{BC} 2$ at all stress levels.

Table 2 Comparison of the simulated total rupture life and percentage change for $45^{\circ}$ welded P91/Inco82 DMW system at different boundary conditions (BCs) and remotely applied loads

\begin{tabular}{|c|c|c|c|c|c|c|}
\hline \multirow{2}{*}{$\begin{array}{c}\text { Applied stresses } \\
\text { (MPa) }\end{array}$} & \multicolumn{3}{|c|}{ Total rupture life (h) } & \multicolumn{3}{c|}{ Percentage change } \\
\cline { 2 - 7 } & BC1 & BC2 (free) & BC3 (full) & BC1 & BC2 (free) & BC3 (full) \\
\hline $\mathbf{1 7 7}$ & 2619 & 2626 & 2627 & 0 & $+0.27 \%$ & $+0.3 \%$ \\
\hline $\mathbf{1 6 0}$ & 4438 & 4440 & 4459 & 0 & $+0.04 \%$ & $+0.43 \%$ \\
\hline $\mathbf{1 2 0}$ & 14566 & 14605 & 14614 & 0 & $+0.27 \%$ & $+0.33 \%$ \\
\hline
\end{tabular}

\subsection{Case study 2 - sensitivity to a pre-existing crack}

All the simulations so far have assumed an intact welded interface with no pre-existing cracks. Here we assume a small preexisting crack at where the interface meets the top free surface and explore how it influences the creep rupture life of the P91/Inco82 DMW system at various applied loads, taking a $45^{\circ}$ weld and the original boundary condition (BC1) as an example. A crack with $0.1 \mathrm{~mm}$ length (1/50 thickness) was created where the interface meets the top free surface (Fig. 5a) in the model by removing two interface elements at the beginning. The applied loads remain the same as in section 5.1, as do all the parameters and the computational procedure.

Table 3 compares the simulated rupture life with and without a pre-existing crack at free edge. Relative percentage changes are also shown in the table. The total rupture life is found, and is expected, to decrease at all the applied loads given a pre-existing crack. The percentage change has a rather uniform level of $\sim 16-19 \%$.

Table 3 Change in creep rupture life for $45^{\circ}$ welded P91/Inco82 DMW system with a 0.1 mm pre-existing crack at free edge, subject to different remotely applied loads (the percentage change is shown in brackets)

\begin{tabular}{|c|c|c|c|}
\hline \multirow{2}{*}{$\begin{array}{c}\text { Applied stresses } \\
(\mathbf{M P a})\end{array}$} & No pre-crack at free edge (BC1) & \multicolumn{2}{|c|}{ With a pre-existing crack at free edge (BC1) } \\
\cline { 2 - 4 } & Total rupture life $(\mathrm{h})$ & Total rupture life $(\mathrm{h})$ & Percentage change \\
\hline $\mathbf{1 7 7}$ & 2619 & 2117 & $-19.2 \%$ \\
\hline $\mathbf{1 6 0}$ & 4438 & 3629 & $-18.2 \%$ \\
\hline $\mathbf{1 2 0}$ & 14566 & 12221 & $-16.1 \%$ \\
\hline
\end{tabular}

Further, taking $160 \mathrm{MPa}$ as an example, the evolution of damage along the intact and pre-cracked interface is shown and compared in Fig. 14. The damage accumulation along the pre-cracked interface is found to be faster close to the crack tip at the free edge compared with the intact interface (Fig. 14a), while that in the interior region is very similar for the two cases. As a result, the crack starts to propagate at a much earlier stage due to the higher stresses generated ahead of the tip of the pre-existing crack during creep. In addition, the entire propagation life for the case with a pre-existing crack ( $129 \mathrm{~h}$, Fig. 14b) becomes longer than for the original case with an initially intact interface ( 40 h, Fig. 14a), since the crack now propagates along a less damaged interface. Finally, it should be noted that technically the percentage of life spent in crack propagation stage becomes greater with increasing 
length of the pre-existing crack. This has been examined and validated in a separate study on a compact-tension (CT) specimen of P91/Inco82 DMW.

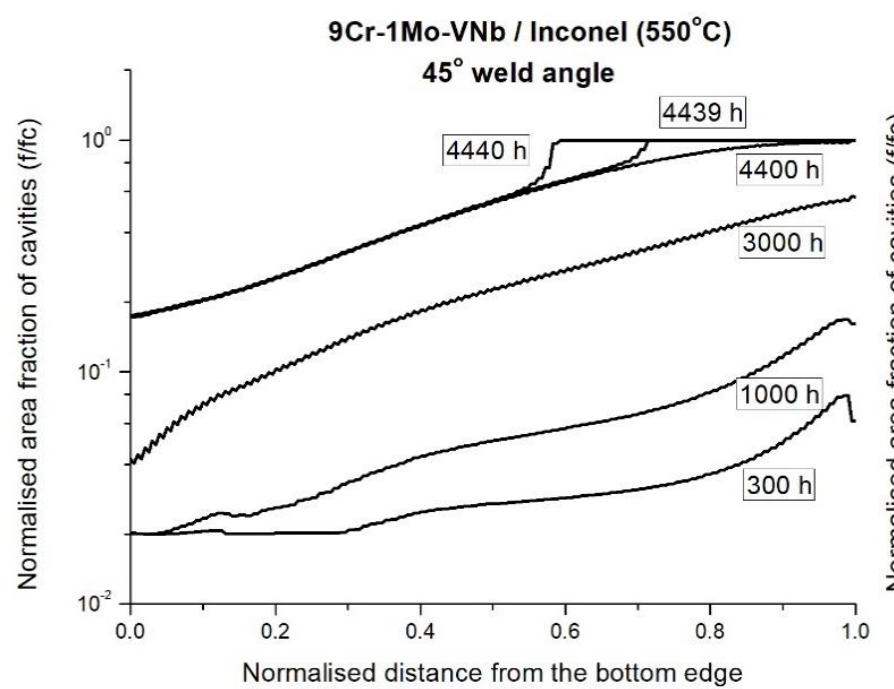

(a)

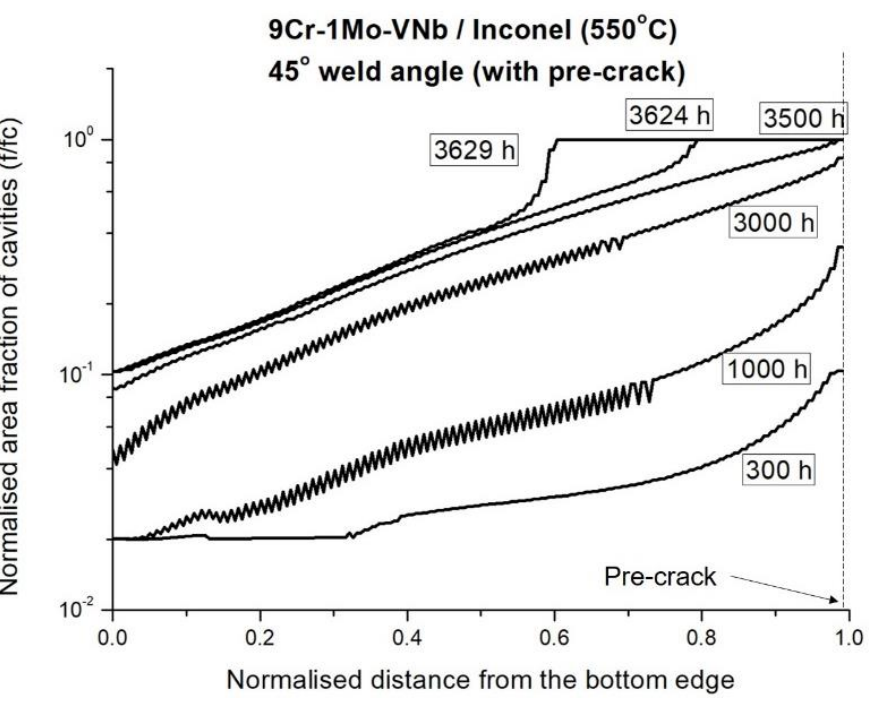

(b)

Fig. 14 Comparison of the evolution of normalised damage accumulation $\left(f / f_{c}\right)$ along the (a) intact and (b) pre-cracked $\left(0.1 \mathrm{~mm}\right.$ at free edge) $45^{\circ}$ welded P91/Inco82 dissimilar interface during creep at $550^{\circ} \mathrm{C}$ subject to a remote load of $160 \mathrm{MPa}$

\subsection{Other sensitivities}

There are other potential sensitivities that are briefly discussed here. Firstly, there are four fitting parameters in Table 1, i.e. two geometrical length-scale parameters, the initial height $\left(h_{0}\right)$ and width $\left(l_{0}\right)$ of the unit cell, one material length-scale parameter, the reference separation rate $\dot{\delta}_{0}$, and the critical cavity fraction $f_{c}$. Constraints of the choice of the three length-scale parameters are discussed in section 4.1. Under these constraints, sensitivity of the creep cavity growth rate (Fig. 11a) to these parameters is explored by changing the value of each parameter while keeping the values of others the same as in Table 1 . It has been found that the cavity growth rate increases with a decrease in $h_{0}$ or with an increase in $\dot{\delta}_{0}$, but is not sensitive to the change in $l_{0}\left(\operatorname{provided} l_{0}>h_{0}\right.$ ). The former can be attributed to the increase in the reference creep rate of the interface elements $\left(\sim \dot{\delta}_{0} / h_{0}\right)$ thus an enhancement of the cavity growth rate. An increase (decrease) in $f_{c}$ does not change the cavity growth but only leads to an increase (decrease) of the total life. It should be noted that the major results presented in this paper, including the majority of life taken by the crack initiation and rupture sequence with different weld angles, remain the same irrespective of these changes in parameters.

Secondly, this study only focused on a simple remote uniaxial loading condition. In practice, a real DMW component may be subjected to complex multiaxial loading conditions. An alternative simple scenario has been examined in which the DMW plate (Fig. 5a) is subjected to a remote friction or pure shear loading instead of uniaxial loading. As a result, the magnitudes of both the normal and tangential tractions close to the interface are altered. Following the same procedure as used in the simplified analysis conducted in section 4.2 for Fig. 11, it is found that a $75^{\circ}$ weld becomes more detrimental than a $60^{\circ}$ weld, while a $30^{\circ}$ weld is still the most beneficial. More complex loading conditions, such as an internal pressure applied on a DMW axisymmetric cylinder pipe, can be found elsewhere [23].

Thirdly, the creep property mismatch adjacent to the dissimilar interface has been fixed in the P91/Inco82 DMW system considered in this study. A sensitivity study of the crack initiation and propagation life of a 90 P91/Inco82 DMW axisymmetric cylinder model to the creep property mismatch has been carried out elsewhere [8]. Changes to the creep mismatch have been found not to alter the total rupture life significantly, but can notably change the ratio of times spent in the crack initiation and propagation stages. A similar effect can also be achieved by changing the dissimilar material (e.g. P22 instead of P91 [8]). It is therefore expected that the general trend remains the same for all other weld angles. 
Finally, it should be noted that apart from the total rupture life data for $90^{\circ}$ and $45^{\circ} \mathrm{DMW}$ components shown in Fig. 2 , no other data is available to validate the results and analyses conducted in this study. Although further experimental validations are needed before the methods can be incorporated into industrial design codes, the current study provides insights regarding the improvement of interface creep rupture life in the structural integrity assessment of DMWs in power plant pipelines.

\section{Conclusion}

In this study, we have developed a physically based interface zone model with a damage variable representing the area fraction of cavities. The model has been coded as an ABAQUS UEL subroutine, which has been used to simulate and evaluate the effect of weld angle on the creep rupture life of P91/Inco82 dissimilar metal welds (DMW) at $550^{\circ} \mathrm{C}$. Under these conditions failure occurs at the dissimilar weld interface between the P91 CGHAZ and Inco82 filler metal. A 2D plane strain model is established with the creep parameters calibrated against experimental data for a $90^{\circ}$ weld angle. The calibrated model is then used to examine damage development and failure of welds with different weld angles $\left(75^{\circ}, 60^{\circ}, 45^{\circ}\right.$ and $\left.30^{\circ}\right)$. Sensitivity studies of rupture life to the boundary conditions employed and to the presence of a pre-existing crack are also conducted, taking a $45^{\circ}$ weld angle as an example. The main findings are summarized below:

(1) Whilst the reduced rupture life of a $45^{\circ}$ weld angle compared with the standard $90^{\circ}$ weld angle is captured, the simulation highlights a more detrimental weld angle of $60^{\circ}$ with an even shorter rupture life, and a more beneficial weld angle of $30^{\circ}$ with

a much longer rupture life, at the temperature and stress range considered in this study. This can be attributed to the combined contribution of normal and tangential tractions to the cavity growth at the interface, i.e. a strong mode mixity.

(2) The majority of the creep rupture life is taken by crack initiation for all the tested weld angles, due to the idealized flat interface. A wavy interface or a step weld concept in a real application with an altering weld path is expected to enable sufficient life fraction in the crack propagation stage, which would increase the probability of crack detection prior to catastrophic failure. Considering (1), the damage tolerance can be further promoted by designing and adopting weld angles smaller than $45^{\circ}$ and avoiding $60^{\circ}$ weld angles in the fabrication of the wavy interface.

(3) Since there is limited development of continuum damage in the CGHAZ and FGHAZ during creep (as measured by the quantity $N / N_{c}$ ) for weld angles below $90^{\circ}$, the diversion of the crack into HAZ is less likely compared with a $90^{\circ}$ weld angle [8]. This indicates a reduced susceptibility to Type VI failure mode in problems with reduced weld angles. The Type IV failure mode in FGHAZ is also unlikely to occur.

(4) The creep rupture life of DMW components can be improved by adopting a fully constrained boundary condition instead of a free boundary condition, but this can only be realised if the interface zone is much softer than the adjacent matrix material.

(5) A pre-existing crack where the interface meets the free surface can reduce the creep rupture life of DMW components. Despite this, it can increase the percentage of the crack propagation life. This is because the crack would propagate along a less damaged interface when it starts to propagate at a much earlier stage as a result of an additional stress concentration generated around the tip of the pre-existing crack during creep.

Further extension of the model framework consists of two aspects: (1) 3D non-axisymmetric solid cylinder actual pipe simulation [23], and (2) a micromechanical approach describing the Type I precipitate formation [4, 14] and its effect on the evolution of cavities at the dissimilar interface.

\section{Acknowledgement}

Jianan Hu, Elsiddig Elmukashfi and Alan Cocks would like to acknowledge the financial support of Mitsubishi Heavy Industries (MHI). 


\section{References}

[1] Clark JWG. Investigating chemical and microstructural evolution at dissimilar metal welds. EngD Thesis. 2015;University of Nottingham.

[2] Hyde TH, Sun W, Becker AA, Williams JA. Effect of weld angle and axial load on the creep failure behaviour of an internally pressurised thick walled CrMoV pipe weld. Int J Pres Ves Pip. 2001;78:365-72.

[3] Siefert J, Parker J, Totemeier T. Complexities of in-service failures in dissimilar metal welds between grade 91 and austenitic stainless steels. Proceedings of the ASME 2016 Pressure Vessels and Piping Conference (PVP2016). 2016;Vancouver.

[4] Laha K, Chandravathi KS, Parameswaran P, Goyal S, Mathew MD. A Comparison of Creep Rupture Strength of Ferritic/Austenitic Dissimilar Weld Joints of Different Grades of Cr-Mo Ferritic Steels. Metallurgical and Materials Transactions a-Physical Metallurgy and Materials Science. 2012;43A:1174-86.

[5] Yamazaki M, Watanabe T, Hongo H, Tabuchi M. Creep rupture properties of welded joints of heat resistant steels. Journal of Power and Energy Systems. 2008;2:1140-9.

[6] Han JJ, Kim SH, Kim YJ, Nikbin K, Dean D. Mismatch effect of creep properties on steady-state stresses for welded straight pipes: quantification and application. Proceedings of the ASME 2013 Pressure Vessels and Piping Conference (PVP2013). 2013;Paris.

[7] Yamashita T, Takaya S, Nagae Y, Date S, Tomobe M. Factor analysis of interface failure mechanism for dissimilar weld joints. Proc the 52nd Symp on Strength of Materials at High Temperatures The Society of Materials Science Japan, Kyoto $2014: 80.2014$. [8] Hu J, Fukahori T, Igari T, Chuman Y, Cocks ACF. Modelling of creep rupture of ferritic/austenitic dissimilar weld interfaces under mode I fracture. Engineering Fracture Mechanics. 2018;191:344-64.

[9] Clark JWG, McCartney DG, Saghafifar H, Shipway PH. Modelling Chemical and Microstructural Evolution across Dissimilar Interfaces in Power Plants. Proceedings of the Asme Power Conference, 2014, Vol 1. 2014.

[10] Zhang Y. Changes in microstructure and mechanical properties of P91 weld metal during creep. Thesis for Nottingham University. 2009.

[11] Mvola B, Kah P, Martikainen J. Dissimilar Ferrous Metal Welding Using Advanced Gas Metal Arc Welding Processes. Reviews on Advanced Materials Science. 2014;38:125-37.

[12] Foret R, Hodis Z, Sopousek J. Redistribution of carbon and nitrogen in heterogeneous weld joints of creep-resistant steels (P91/P22). 21st International Conference on Metallurgy and Materials (METAL 2012). 2012:478-84.

[13] Al Hajri M, Malik AU, Meroufel A, Al-Muaili F. Premature failure of dissimilar metal weld joint at intermediate temperature superheater tube. Case Studies in Engineering Failure Analysis. 2015;3:96-103.

[14] DuPont JN. Microstructural evolution and high temperature failure of ferritic to austenitic dissimilar welds. International Materials Reviews. 2012;57:208-34.

[15] Konar R, Patek M. Numerical Simulation of Dissimilar Weld Joint in Sysweld Simulation Software. Teh Vjesn. 2017;24:13742.

[16] Akella S, Harinadh V, Krishna Y, Buddu RK. A Welding simulation of dissimilar materials SS304 and Copper. Proc Mat Sci. 2014;5:2440-9.

[17] Szavai S, Bezi Z, Rozsahegyi P. Material Characterization and Numerical Simulation of a Dissimilar Metal Weld. Procedia Struct Inte. 2016;2:1023-30.

[18] Esfahani MRN, Coupland J, Marimuthu S. Numerical simulation of alloy composition in dissimilar laser welding. J Mater Process Tech. 2015;224:135-42.

[19] Champion CR, Atkinson C. A Crack at the Interface between 2 Power-Law Materials under Plane-Strain Loading. P Roy Soc Lond a Mat. 1991;432:547-53.

[20] Fukahori T, Tokiyoshi T, Chuman Y, Igari T, Saito N, Hirakawa Y, et al. Experimental study on the creep failure modes of dissimilar metal welds. Presented in EPRI Workshop on "Dissimilar Welds in High Temperature Applications" held in Collaboration with ASME PVP. 2017.

[21] Hu J, Fukahori T, Igari T, Chuman Y, Cocks ACF. An evaluation of creep rupture strength of ferritic/austenitic dissimilar weld interfaces using cohesive zone modelling. Procedia Structural Integrity. 2016;2:934-41.

[22] Yalcinkaya T, Cocks ACF. Micromechanical cohesive zone relations for ductile fracture. Procedia Structural Integrity. 2016;2:1716-23.

[23] Elmukashfi E, Fukahori T, Igari T, Chuman Y, Cocks ACF. A 3D finite element study of the effect of weld angle on the creep rupture life of ferritic/austenitic dissimilar weld interfaces. To appear. 2019.

[24] Kumar Y, Venugopal S, Sasikala G, Albert SK, Bhaduri AK. Study of creep crack growth in a modified 9Cr-1Mo steel weld metal and heat affected zone. Materials Science and Engineering a-Structural Materials Properties Microstructure and Processing. 2016;655:300-9.

[25] Eggeler G, Ramteke A, Coleman M, Chew B, Peter G, Burblies A, et al. Analysis of Creep in a Welded P91 Pressure-Vessel. Int J Pres Ves Pip. 1994;60:237-57.

[26] Lim R, Sauzay M, Dalle F, Tournie I, Bonnaillie P, Gourgues-Lorenzon AF. Modelling and experimental study of the tertiary creep stage of Grade 91 steel. International Journal of Fracture. 2011;169:213-28.

[27] Mannan SL, Laha K. Creep behaviour of Cr-Mo steel weldments. Transactions of the Indian Institute of Metals. 1996;49:30320.

[28] Gonzalez D, Cocks ACF, Fukahori T, Igari T, Chuman Y. Creep failure of a P91 simulated heat affected zone material under multiaxial state of stress. Proceedings of 3rd International ECCC Conference on Creep \& Fracture. 2014. 
[29] Igari T, Fukahori T, Kawashima F, Tokiyoshi T, Chuman Y, Komai N, et al. Micro-macro creep damage simulation for welded joints. Mater High Temp. 2011;28:181-7.

[30] Fukahori T, Tokiyoshi T, Igari T, Chuman Y, Komai N. Prediction of Type IV creep failure of a seam-welded mod. 9Cr-1Mo elbow based on microscopic damage simulation. Mater High Temp. 2017;34:194-207.

[31] Kawashima F, Igari T, Tokiyoshi T, Shiibashi A, Tada N. Micro-macro combined simulation of the damage progress in lowalloy steel welds subject to type IV creep failure. Jsme International Journal Series a-Solid Mechanics and Material Engineering. 2004;47:410-8.

[32] Mcclintock FA. Local Criteria for Ductile Fracture. Int J Fract Mech. 1968;4:101-30.

[33] Cocks ACF, Ashby MF. Intergranular Fracture during Power-Law Creep under Multiaxial Stresses. Metal Science. $1980 ; 14: 395-402$.

[34] Cocks ACF. Inelastic Deformation of Porous Materials. Journal of the Mechanics and Physics of Solids. 1989;37:693-715.

[35] Cocks ACF, Pan J. The Influence of an Interface Reaction on the Creep Response of Damaged Materials. Mechanics of Materials. 1994;18:269-87.

[36] Wen JF, Tu ST, Gao XL, Reddy JN. Simulations of creep crack growth in 316 stainless steel using a novel creep-damage model. Engineering Fracture Mechanics. 2013;98:169-84.

[37] Chen G, Wang GZ, Zhang JW, Xuan FZ, Tu ST. Effects of initial crack positions and load levels on creep failure behavior in P92 steel welded joint. Eng Fail Anal. 2015;47:56-66.

[38] Chen G, Wang GZ, Xuan FZ, Tu ST. Effects of HAZ widths on creep crack growth properties of welded joints. Weld World. 2015;59:851-60.

[39] Chen G, Wang GZ, Xuan FZ, Tu ST. Mismatch effect in creep properties on creep crack growth behavior in welded joints. Mater Design. 2014;63:600-8.

[40] Segle P, Andersson P, Samuelson A. Numerical investigation of creep crack growth in cross-weld CT specimens. Part I: influence of mismatch in creep deformation properties and notch tip location. Fatigue Fract Eng M. 2000;23:521 -31.

[41] Lee KH, Kim YJ, Yoon KB, Nikbin K, Dean D. Quantification of stress redistribution due to mismatch in creep properties in welded branch pipes. Fatigue Fract Eng M. 2010;33:238-51.

[42] Francis JA, Mazur W, Bhadeshia HKDH. Type IV cracking in ferritic power plant steels. Materials Science and Technology. 2006;22:1387-95.

[43] Laha K, Chandravathi KS, Parameswaran P, Rao KBS, Mannan SL. Characterization of microstructures across the heat-affected zone of the modified $9 \mathrm{Cr}-1$ Mo weld joint to understand its role in promoting type IV cracking. Metallurgical and Materials Transactions a-Physical Metallurgy and Materials Science. 2007;38A:58-68.

\section{Appendix Computational scheme for the mix-mode cohesive zone models}

For the physical interface zone model considering cavity growth (Eqs. 14 and 16), the update of normal and tangential tractions $\left(T_{n}, T_{t}\right)$ and separations $\left(\delta_{n}, \delta_{t}\right)$ at each time increment in UEL through Newton-Raphson iteration method is given below.

At the beginning of each time increment, the initial values of $T_{n}, T_{t}, \delta_{n}^{c r}, \delta_{t}^{c r}$ are given from the last time increment, while the total separation increments $\Delta \delta_{n}, \Delta \delta_{t}$ are given from ABAQUS. The incremental formulation of the total, elastic and creep separation increments can be written as

$$
\begin{aligned}
& \Delta \delta_{x}=\Delta \delta_{x}^{e}+\Delta \delta_{x}^{c r} \\
& \Delta \delta_{x}^{e}=a \Delta T_{x} \\
& \Delta \delta_{x}^{c r}=\dot{\delta}_{0} \Delta t\left(\frac{T_{e}}{T_{0}}\right)^{m} \cdot \frac{\partial T_{e}}{\partial T_{x}}=\left(\frac{\dot{\delta}_{0}}{T_{0}{ }^{m}}\right) \Delta t T_{e}^{m-1} T_{x} \frac{1}{g_{x}}
\end{aligned}
$$

The subscript " $x$ " is " $n$ " for normal direction and " $t$ " for tangential direction. $T_{e}$ is the effective traction described in Eq. (10), $g_{n}$ and $g_{t}$ are functions of volume fraction of cavities $f$ as shown in Eq. (10), $g_{n}=\left[(1-f)^{2}+(\ln f)^{2} / 3\right], g_{t}=\left[(1-f)^{2} / 3\right]$. The incremental formulation of $f$ and $h$ can be written as 


$$
\begin{aligned}
& \Delta f=\frac{\Delta \delta_{n}^{c r}}{h}(1-f)+\sqrt{f} \frac{\Delta \delta_{t}^{c r}}{l} \\
& \Delta h=\Delta \delta_{n}^{c r}-\frac{h}{l \sqrt{f}} \Delta \delta_{t}^{c r}
\end{aligned}
$$

Four unknowns ( $\Delta T_{n}, \Delta T_{t}, \Delta \delta_{n}^{c r}, \Delta \delta_{t}^{c r}$ ) require four equations to solve, which are given as follows:

$$
\begin{aligned}
& H_{n}=\Delta \delta_{n}-a \Delta T_{n}-\Delta \delta_{n}^{c r}=0 \\
& H_{t}=\Delta \delta_{t}-a \Delta T_{t}-\Delta \delta_{t}^{c r}=0 \\
& G_{n}=\Delta \delta_{n}^{c r}-b \Delta t T_{e}^{m-1} T_{n} \cdot \frac{1}{g_{n}}=0 \\
& G_{t}=\Delta \delta_{t}^{c r}-b \Delta t T_{e}^{m-1} T_{t} \cdot \frac{1}{g_{t}}=0
\end{aligned}
$$

where $b=\dot{\delta}_{0} / T_{0}{ }^{m}$. Note that the quantities $T_{n}, T_{t}, g_{n}, g_{t}$ are all evaluated at an instant $\theta \Delta t$, i.e. $T_{x}=T_{x}(t+\theta \Delta t), g_{x}=g_{x}(t+\theta \Delta t)=$ $g_{x}(f+\theta \Delta f)$ where $\theta$ is an integration constant chosen to be 0.5 in the current simulation. Thus the system equation can be written in a vector form as $F(X)=0$ where $F=\left[\begin{array}{llll}H_{n} & H_{t} & G_{n} & G_{t}\end{array}\right]^{T}$ and $X=\left[\begin{array}{llll}\Delta \delta_{t}^{c r} & \Delta \delta_{n}^{c r} & \Delta T_{t} & \Delta T_{n}\end{array}\right]^{T}$. In order to solve this set of nonlinear equations, Newton method is needed.

$$
F(X+\delta X) \approx F(X)+\frac{\partial F}{\partial X} \cdot \delta X=0
$$

Note that each equation in Eq. (A5) is a function of all the four unknowns. Thus the Jacobian matrix is a fourth order matrix.

$$
[J(X)]=\frac{\partial F}{\partial X}=\left[\begin{array}{cccc}
\frac{\partial H_{n}}{\partial \Delta \delta_{n}^{c r}} & \frac{\partial H_{n}}{\partial \Delta \delta_{t}^{c r}} & \frac{\partial H_{n}}{\partial \Delta T_{n}} & \frac{\partial H_{n}}{\partial \Delta T_{t}} \\
\frac{\partial H_{t}}{\partial \Delta \delta_{n}^{c r}} & \frac{\partial H_{t}}{\partial \Delta \delta_{t}^{c r}} & \frac{\partial H_{t}}{\partial \Delta T_{n}} & \frac{\partial H_{t}}{\partial \Delta T_{t}} \\
\frac{\partial G_{n}}{\partial \Delta \delta_{n}^{c r}} & \frac{\partial G_{n}}{\partial \Delta \delta_{t}^{c r}} & \frac{\partial G_{n}}{\partial \Delta T_{n}} & \frac{\partial G_{n}}{\partial \Delta T_{t}} \\
\frac{\partial G_{t}}{\partial \Delta \delta_{n}^{c r}} & \frac{\partial G_{t}}{\partial \Delta \delta_{t}^{c r}} & \frac{\partial H_{t}}{\partial \Delta T_{n}} & \frac{\partial H_{t}}{\partial \Delta T_{t}}
\end{array}\right]
$$

After $i+1$ iterations within the increment the value of $X^{i+1}$ is given by

$$
X^{i+1}=\left\{\begin{array}{c}
\Delta \delta_{n}^{c r} \\
\Delta \delta_{t}^{c r} \\
\Delta T_{n} \\
\Delta T_{t}
\end{array}\right\}^{i+1}=\left\{\begin{array}{c}
\Delta \delta_{n}^{c r} \\
\Delta \delta_{t}^{c r} \\
\Delta T_{n} \\
\Delta T_{t}
\end{array}\right\}-[J(X)]^{i}\left\{\begin{array}{c}
H_{n} \\
H_{t} \\
G_{n} \\
G_{t}
\end{array}\right\}
$$

The iteration process continues until a prescribed tolerance is reached for $X$. Further, $\partial T / \partial \delta$, or $\partial \Delta T / \partial \Delta \delta$, can be determined by differentiating $\mathrm{F}(\mathrm{X})$ with respect to $\Delta \delta_{n}, \Delta \delta_{t}$ 


$$
\begin{aligned}
& {\left[\begin{array}{llll}
\frac{\partial H_{n}}{\partial \Delta \delta_{n}^{c r}} & \frac{\partial H_{n}}{\partial \Delta \delta_{t}^{c r}} & \frac{\partial H_{n}}{\partial \Delta T_{n}} & \frac{\partial H_{n}}{\partial \Delta T_{t}} \\
\frac{\partial H_{t}}{\partial \Delta \delta_{n}^{c r}} & \frac{\partial H_{t}}{\partial \Delta \delta_{t}^{c r}} & \frac{\partial H_{t}}{\partial \Delta T_{n}} & \frac{\partial H_{t}}{\partial \Delta T_{t}} \\
\frac{\partial G_{n}}{\partial \Delta \delta_{n}^{c r}} & \frac{\partial G_{n}}{\partial \Delta \delta_{t}^{c r}} & \frac{\partial G_{n}}{\partial \Delta T_{n}} & \frac{\partial G_{n}}{\partial \Delta T_{t}} \\
\frac{\partial G_{t}}{\partial \Delta \delta_{n}^{c r}} & \frac{\partial G_{t}}{\partial \Delta \delta_{t}^{c r}} & \frac{\partial H_{t}}{\partial \Delta T_{n}} & \frac{\partial H_{t}}{\partial \Delta T_{t}}
\end{array}\right] \cdot\left\{\begin{array}{l}
\frac{\partial \Delta \delta_{n}^{c r}}{\partial \Delta \delta_{n}} \\
\frac{\partial \Delta \delta_{t}^{c r}}{\partial \Delta \delta_{n}} \\
\frac{\partial \Delta T_{n}}{\partial \Delta \delta_{n}} \\
\frac{\partial \Delta T_{t}}{\partial \Delta \delta_{n}}
\end{array}\right\}=[J(X)]\left\{\begin{array}{l}
\frac{\partial \Delta \delta_{t}^{c r}}{\partial \Delta \delta_{n}} \\
\frac{\partial \Delta T_{n}}{\partial \Delta \delta_{n}} \\
\frac{\partial \Delta T_{t}}{\partial \Delta \delta_{n}}
\end{array}\right\}=\left\{\begin{array}{l}
1 \\
0 \\
0 \\
0
\end{array}\right\}} \\
& {\left[\begin{array}{llll}
\frac{\partial H_{n}}{\partial \Delta \delta_{n}^{c r}} & \frac{\partial H_{n}}{\partial \Delta \delta_{t}^{c r}} & \frac{\partial H_{n}}{\partial \Delta T_{n}} & \frac{\partial H_{n}}{\partial \Delta T_{t}} \\
\frac{\partial H_{t}}{\partial \Delta \delta_{n}^{c r}} & \frac{\partial H_{t}}{\partial \Delta \delta_{t}^{c r}} & \frac{\partial H_{t}}{\partial \Delta T_{n}} & \frac{\partial H_{t}}{\partial \Delta T_{t}} \\
\frac{\partial G_{n}}{\partial \Delta \delta_{n}^{c r}} & \frac{\partial G_{n}}{\partial \Delta \delta_{t}^{c r}} & \frac{\partial G_{n}}{\partial \Delta T_{n}} & \frac{\partial G_{n}}{\partial \Delta T_{t}} \\
\frac{\partial G_{t}}{\partial \Delta \delta_{n}^{c r}} & \frac{\partial G_{t}}{\partial \Delta \delta_{t}^{c r}} & \frac{\partial H_{t}}{\partial \Delta T_{n}} & \frac{\partial H_{t}}{\partial \Delta T_{t}}
\end{array}\right] \cdot\left\{\begin{array}{l}
\frac{\partial \Delta \delta_{n}^{c r}}{\partial \Delta \delta_{t}} \\
\frac{\partial \Delta \delta_{t}^{c r}}{\partial \Delta \delta_{t}} \\
\frac{\partial \Delta T_{n}}{\partial \Delta \delta_{t}} \\
\frac{\partial \Delta T_{t}^{c r}}{\partial \Delta \delta_{t}}
\end{array}\right\}=[J(X)]\left\{\begin{array}{l}
\frac{\partial \Delta \delta_{t}}{\partial \Delta T_{n}} \\
\frac{\partial \Delta \delta_{t}}{\partial \Delta T_{t}} \\
\frac{\partial \Delta \delta_{t}}{\partial}
\end{array}\right\}=\left\{\begin{array}{l}
0 \\
1 \\
0 \\
0
\end{array}\right\}}
\end{aligned}
$$

Given the value of Jacobian matrix $[\mathrm{J}(\mathrm{X})]$ determined in the final iteration in the time increment, $\partial T / \partial \delta$ can be then computed by Eqs. (A9) and (A10).

$$
\frac{\partial T}{\partial \delta}=\frac{\partial \Delta T}{\partial \Delta \delta}=\left[\begin{array}{ll}
\frac{\partial \Delta T_{n}}{\partial \Delta \delta_{n}} & \frac{\partial \Delta T_{n}}{\partial \Delta \delta_{t}} \\
\frac{\partial \Delta T_{t}}{\partial \Delta \delta_{n}} & \frac{\partial \Delta T_{t}}{\partial \Delta \delta_{t}}
\end{array}\right]
$$

